Revista Universo Contábil, ISSN 1809-3337
Blumenau, v. 14, n. 2, p. 30-60, abr.jun., 2018
doi:10.4270/ruc.2018210
Disponivel em www.furb.br/universocontabil

\title{
RETORNO DAS AÇÕES E SENSIBILIDADE AO RISCO DE MERCADO DAS EMPRESAS PARTICIPANTES DO ÍNDICE CARBONO EFICIENTE (ICO2) DA B3 S.A.: UM ESTUDO COMPARATIVO ${ }^{1}$
}

\author{
RETURN OF SHARES AND SENSITIVITY TO MARKET RISK OF THE CARBON \\ EFFICIENT INDEX (CEI2) COMPANY (ICO2) OF B3 S.A.: A COMPARATIVE STUDY \\ RENDIMIENTOS DE LAS ACCIONES Y LA SENSIBILIDAD AL RIESGO DEL \\ MERCADO DE LAS EMPRESAS QUE PARTICIPAN EN EL ÍNDICE DE CARBONO \\ EFICIENTE (ICO2) DE LA B3 S.A.: UN ESTUDIO COMPARATIVO
}

\begin{abstract}
André Luis Rocha de Souza
Doutor em Engenharia Industrial pela Universidade Federal da Bahia Professor do Departamento de Ciências Sociais Aplicadas do Instituto Federal da Bahia Endereço: Rua Emídio dos Santos, S/N - Barbalho CEP: 40301-015 - Salvador - BA - Brasil

E-mail: andre_financas@yahoo.com.br Telefone: (71) 2102-9530
\end{abstract}

Antônio Francisco de Almeida da Silva Junior

Doutor em Engenharia Aeronáutica e Mecânica pelo Instituto Tecnológico de Aeronáutica Professor do Núcleo de Pós-Graduação em Administração da Universidade Federa da Bahia Endereço: Av. Reitor Miguel Calmon, S/N - Vale do Canela CEP: 40110-903 - Salvador - BA - Brasil

E-mail: afranc13@hotmail.com Telefone: (71) 3283-7340

José Célio Silveira Andrade

Doutor em Administração pela Universidade Federal da Bahia Professor do Núcleo de Pós-Graduação em Administração da Universidade Federa da Bahia Endereço: Av. Reitor Miguel Calmon, S/N - Vale do Canela CEP: 40110-903 - Salvador - BA - Brasil

E-mail: jcelio.andrade@gmail.com

Telefone: +55 (71) 3283-7340

Maria Eduarda da Silva Teixeira Fernandes

Doutora em Ciências Económicas pela Universidade do Minho Professora da Escola Superior de Tecnologia e Gestão do Instituto Politécnico de Leiria Endereço: Campus 2 - Morro do Lena - Alto do Vieiro- Apt. 4163 - Leiria - Portugal E-mail: eduarda.fernandes@ipleiria.pt Telefone: + 351244843320

\footnotetext{
${ }^{1}$ Artigo recebido em 19/05/2017. Revisado por pares em 10/09/2018. Reformulado em 07/11/2018. Recomendado para publicação em 27/11/2018 por Tarcísio Pedro da Silva. Publicado em 20/02/2019. Organização responsável pelo periódico: FURB.
} 


\section{RESUMO}

Essa pesquisa objetivou examinar qual a relação entre a participação das empresas no ICO2/B3 e o retorno e sensibilidade de suas ações ao risco de mercado visando subsidiar a tomada de decisão por parte de empresas e investidores. A motivação da pesquisa consiste em avaliar se empresas que decidem participar do ICO2 têm benefícios de maiores retornos e/ou menor risco de mercado, o que poderia induzir a decisão das firmas em aderirem ao ICO2 e influenciaria a decisão dos investidores em suas alocações de ativos. Para alcançar o objetivo proposto, realizaram-se dois estudos, denominados de estudo "a" e estudo "b". No estudo "a" adotou-se técnicas estatísticas de regressão pelo modelo dos MQO e em painel com a finalidade de comparar o desempenho entre empresas que ingressaram no ICO2 (27) e empresas que não ingressaram (8). Já no estudo "b" utilizou-se de técnicas estatísticas de regressão SUR para análise dos retornos e riscos individuais, além de MQO e em painel, cuja análise focou-se no grupo de empresas que ingressou no ICO2 (27), para examinar o período pré e pós-admissão no índice. Os resultados evidenciaram que as empresas que ingressaram no ICO2 não apresentaram retornos das ações superiores em comparação ao grupo de empresas que não ingressou no ICO2, mas apresentaram menor sensibilidade ao risco de mercado do que o grupo de empresas que não ingressou no índice. Além disso, a análise focada apenas nas empresas que participavam do índice não evidenciou uma mudança de comportamento nos retornos e na sensibilidade ao risco de mercado das ações desse grupo de empresas após ingressarem no índice em comparação ao período que antecedeu a sua entrada na iniciativa. Assim, os resultados sugerem que empresas menos sensíveis ao risco de mercado são mais propensas à adesão ao ICO2 e essa adesão não necessariamente implica maiores retornos financeiros.

Palavras-chave: Mudanças Climáticas, Índice Carbono Eficiente (ICO2), Retorno das Ações, Sensibilidade ao Risco de Mercado.

\section{ABSTRACT}

This research aimed to examine the relationship between company participation in CEI2/B3 and return and sensitivity of their stocks to market risk in order to support decision making by companies and investors. The aim of the research is to evaluate if companies in CEI2/B3 have higher returns and lower risks than companies that are not in the index, which would induce more firms in the index and would impact the investors asset allocation. To attain this objective, two studies were carried out, denominated study "a" and study "b". In the study "a", regression statistical techniques was adopted by the model of OLS (MQO) and panel model to compare performance among companies that entered the CEI2 (27) and companies that did not participate in this index (8). In relation to the study "b", statistical techniques used were regression SUR for the analysis of individual returns and risks, as well as the OLS and panel, there was an analysis of the group of companies that entered the CEI2 (27), to examine the before and after admission to the index. The group of companies that entered the CEI 2 did not present high returns on their investments compared to the group of companies that did not participate in this index, but did present less sensitivity to market risk than the group of companies that have not joined the index. In addition, the analysis focused only on companies participating in the index did not show a change in behavior in the returns and sensitivity to market risk of the stocks this group of companies after joining the index compared to the period before they entered the initiative. The results of this research suggest that companies with lower market risks are more likely to be in the index and that they have not higher returns.

Keywords: Climate Change, Carbon Efficient Index (CEI2), Return on Investments, Sensitivity to Market Risk. 
RETORNO DAS AÇÕES E SENSIBILIDADE AO RISCO DE MERCADO DAS EMPRESAS

PARTICIPANTES DO ÍNDICE CARBONO EFICIENTE (ICO2) DA B3 S.A.: UM ESTUDO

COMPARATIVO

\section{RESUMEN}

Esta investigación tuvo por objetivo examinar cuál es la relación entre la participación de las empresas en el ICO2/B3 y el retorno y sensibilidad de acciones al riesgo de mercado para subsidiar la toma de decisión por parte de empresas e inversores. La motivación de la investigación es evaluar si las empresas que deciden participar en el ICO2 tienen beneficios de mayores retornos y / o menor riesgo de mercado, lo que podría inducir la decisión de las firmas en adherirse al ICO2 e influir en la decisión de los inversores en sus asignaciones de activos. Para alcanzar el objetivo propuesto, se realizaron dos estudios, denominados de estudio "a" y estudio "b". En el estudio "a" se adoptaron técnicas estadísticas de regresión por el modelo de los MQO y en panel con la finalidad de comparar el desempeño entre empresas que ingresaron en el ICO2 (27) y empresas que no ingresaron (8). En el estudio "b" se utilizó técnicas estadísticas de regresión $S U R$ para análisis de los retornos y riesgos individuales, además de MQO y en panel, cuyo análisis se enfocó en el grupo de empresas que ingresaron en el ICO2 (27) para examinar el período pre y post-admisión en el índice. Los resultados del primer estudio mostraron que las empresas que entraron en el ICO2 no presentaron rendimientos superiores en comparación con el grupo de empresas que no se han unido, pero que aquellas primeras empresas tenían una menor sensibilidad al riesgo de mercado. Además, en el según estudio, se demostró que las empresas que participan en el índice no presentaran un cambio en el comportamiento de sus rendimientos y de su sensibilidad al riesgo del mercado de valores antes y después de la entrada en el índice. Así, los resultados sugieren que las empresas menos sensibles al riesgo de mercado son más propensas a la adhesión al ICO2 y esa adhesión no necesariamente implica mayores retornos financieros.

Palabras clave: Cambios Climáticos, Índice de Carbono Eficiente (ICO2), Rendimientos de las acciones, Sensibilidad al riesgo del mercado.

\section{INTRODUÇÃO}

É notável que as mudanças climáticas são uma realidade. Os riscos trazidos por esse fenômeno podem alcançar todos os setores da sociedade e requerem ações conjuntas e estratégicas entre governos, empresas e sociedade civil para que sejam mitigados (IPCC, 2013).

O contexto de riscos trazido pelas mudanças climáticas apresenta-se como uma ameaça para as empresas, em virtude dos impactos no retorno dos seus investimentos, no desempenho corporativo e no valor agregado para acionistas e investidores, além dos efeitos catastróficos ao meio ambiente e às pessoas e o aumento da pressão de seus stakeholders, como acionistas, investidores, governo, clientes, fornecedores, credores, dentre outros, que direta e indiretamente possuem interesses na performance corporativa (LABATT; WHITE, 2007; ZIEGLER, 2012; IPCC, 2013; BUOSI, 2014; MISANI; POGUTZ, 2015; SOUZA, 2016; SOUZA et al., 2018).

Esse cenário tem desafiado as organizações a: (i) formular estratégias corporativas sustentáveis; (ii) criar novas tendências no mercado; (iii) desenvolver produtos e serviços resilientes a esse novo cenário; e (iv) adequar as suas atividades visando a transição para uma economia de baixo carbono, uma vez que esta impõe restrições que podem afetar as atividades corporativas e já vem ganhando foco nos principais mercados globais, a exemplo dos mercados americano, chinês, europeu e na América Latina (BOYD; BOYKOFF; NEWELL, 2011; NEWELL; BOYKOFF; BOYD, 2012). Não considerar tais desafios em suas estratégias poderá gerar perda de competitividade e redução da participação de mercado (FARIAS, 2013; PINKSE; KOLK, 2009). A BM\&FBOVESPA et al. (2012) ressaltam que a adoção de estratégias de sustentabilidade deve ser robusta e não deve se limitar, apenas, a respostas aos riscos regulatórios, pois não geram resultados financeiros decorrentes desse tipo de prática.

Segundo Andrade et al. (2013) e Orsato (2009), essa perspectiva demanda estratégias corporativas de sustentabilidade. Tais estratégias incluem a configuração e implementação de 
iniciativas e ações de mitigação e adaptação (FUCHS, 2008; FUCHS; MACEDO; RUSSO, 2009; RONALD; LYNCH, 2010; IPCC, 2013), que gerem vantagens econômicas, financeiras e reputacionais (KOLK; LEVY; PINKSE, 2008; PINKSE; KOLK, 2009); a utilização de instrumentos de disclosure adequados, que sejam transparentes, consistentes e tempestivos, ajudando na redução da percepção do risco corporativo pelos investidores e demais stakeholders (TEIXEIRA; NOSSA; FUNCHAL, 2011; PAGE; HURTT; THOMSON, 2013; SOUZA, 2016); e a realização de investimentos sustentáveis com mudanças de processos (BM\&FBOVESPA et al., 2012); além de contemplar questões relacionadas com a melhoria da reputação, imagem e legitimação de práticas, conforme aponta Farias (2013).

Com relação à utilização de instrumentos de disclosure, observa-se que essa prática vem aumentando nos últimos anos em razão da necessidade de aumentar a divulgação de informações relacionadas às mudanças climáticas em face dos riscos trazidos pelo fenômeno e de pressões dos stakeholders (PINKSE; KOLK, 2009; GOMES, 2012; DIAS-FILHO, 2012; CRUZ, 2015). Em particular, os investidores institucionais têm cobrado das empresas a evidenciação de informações relacionadas à performance corporativa em sustentabilidade o que tem gerado a necessidade de indicadores que permitam tal mensuração (BM\&FBOVESPA et al., 2012).

Segundo Ziegler, Busch e Hoffman (2011) as organizações que adotam práticas de disclosure contribuem para o estreitamento das relações entre empresas e governo, contando positivamente no envolvimento político na conformação de marcos regulatórios relacionados à política climática. Os autores destacam, também, que as empresas que divulgam as suas respostas às mudanças climáticas são bem vistas pelos investidores que podem considerá-las como as de desempenho em sustentabilidade superior quando comparado às empresas que nada divulgam. Assim, observa-se que nos últimos anos vêm crescendo o número de empresas que tem formulado e implementado políticas de sustentabilidade e mudanças climáticas, incorporando-as em seus modelos de negócios, conforme destacaram Cruz et al. (2017).

Nesse sentido, verifica-se no cenário internacional e nacional que as organizações têm se inserido em iniciativas empresariais em clima a exemplo do Carbon Disclosure Project (CDP), World Business Council for Sustainable Development (WBCSD), Global Compact, em índices de sustentabilidade (criado pelas maiores bolsas de valores do mundo, a exemplo do Dow Jones Sustainability Index World - DJSI e o Carbon Efficient Index - CEI ambos da Bolsa de Nova York). Essas iniciativas trazem como ganhos para essas empresas a possibilidade de melhorar a sua legitimidade, imagem e reputação, de refletir e melhorar as suas práticas de gestão, adequar as suas práticas às tendências de mercado. Ademais, tais iniciativas são utilizadas, também, como instrumentos de disclosure em decorrência da credibilidade no mercado e de mensuração de desempenho em sustentabilidade, além de servir como meios (canal) para negociação das suas ações (nos casos dos índices de sustentabilidade e fundos de investimentos a eles vinculados) (PINKSE; KOLK, 2009; ZIEGLER, 2012; BM\&FBOVESPA et al., 2012; FARIAS, 2013; CDP, 2014; SOUZA et al., 2018).

Em relação aos índices de sustentabilidade, acredita-se que a participação das organizações nessas iniciativas pode contribuir para a melhoria da transparência, ganhos reputacionais e legitimidade corporativa, para a adição de valor às suas ações (papéis) negociadas em bolsas (CDP, 2014; ANDRADE et al., 2013; AMARAL, 2012; ZIEGLER, 2012), gerar desempenho financeiro superior (em longo prazo) e influenciar na sensibilidade desses papéis ao risco de mercado (BASSEN; MEYER; SCHLANGE, 2006; KOLK; LEVY; PINKSE, 2008; TEIXEIRA; NOSSA; FUNCHAL 2011; MILANI et al., 2012). Acredita-se, também, que as práticas de gestão corporativas possam ser melhoradas, a partir das exigências e feedbacks dessas iniciativas, que tendem a ser compartilhadas, o que pode gerar tendências no mercado (BARBOSA et al., 2013; BM\&FBOVESPA et al., 2012; ZIEGLER; BUSCH; HOFFMANN, 2011; CAVALCANTE; BRUNI; COSTA, 2009), além de gerar oportunidades 
RETORNO DAS AÇÕES E SENSIBILIDADE AO RISCO DE MERCADO DAS EMPRESAS PARTICIPANTES DO ÍNDICE CARBONO EFICIENTE (ICO2) DA B3 S.A.: UM ESTUDO COMPARATIVO

de obtenção de recursos - considerando que as instituições financeiras têm inserido a variável sustentabilidade dentre os critérios para financiamento de projetos de investimentos, em observância ao Princípio do Equador.

No Brasil, existem dois índices de sustentabilidade: o Índice de Sustentabilidade Empresarial- ISE (criado em 2005 - o quarto índice lançado em nível global e o primeiro da América Latina) e o Índice Carbono Eficiente - ICO2 (criado em 2010 - O primeiro da América Latina), ambos criados pela Bolsa de Valores, Mercadorias e Futuros de São Paulo BM\&FBOVESPA, que mais recentemente, ao realizar combinação de negócios com a Balcão Organizado de Ativos e Derivativos - CETIP, passou a ser chamada de Brasil, Bolsa, Balcão (B3 S.A.) (B3, 2018b; SOUZA, 2016; SOUZA et al., 2018).

Apesar da existência desses dois índices de sustentabilidade no Brasil, que datam, respectivamente, de 2005 e 2010, até o fechamento do presente artigo, observou-se que as pesquisas desenvolvidas até então não respaldam a tomada de decisão por parte de empresas no que se refere ao ingresso ou não nesses índices de sustentabilidade, bem como por parte de investidores, quanto a alocação de recursos em empresas que participam ou não dessas iniciativas por não evidenciarem, de maneira clara, os benefícios relacionados a essas decisões, a exemplo das pesquisas de Rezende, Nunes e Portela (2008), Cavalcante, Bruni e Costa (2009), Lourenço et al., (2011), Amaral (2012), Ziegler (2012), Barbosa et al., (2013) e Cruz (2015). Logo, diante do contexto descrito acima, este artigo visa responder a seguinte pergunta: Qual a relação entre a participação das empresas no ICO2/B3 e o retorno e a sensibilidade de suas ações ao risco de mercado?

Responder a esse problema de pesquisa é relevante tanto do ponto de vista teórico, quanto prático. Do ponto de vista prático, é importante para os investidores saberem se os índices de sustentabilidade provocam alterações no retorno e na sensibilidade das ações ao risco de mercado, ou seja, se eles são ou não recompensados por investirem em empresas participantes de índices de sustentabilidade. Ademais, é crucial para as empresas que fazem parte desses índices de sustentabilidade saberem se vale a pena participarem desse tipo de iniciativa quando comparadas com empresas não participantes. Caso a participação no ICO2 implique maior retorno e menor risco de mercado, isso induz maior participação de firmas no índice e implica impactos positivos na alocação desses ativos nas carteiras dos investidores.

Do ponto de vista teórico, essa pesquisa é relevante, uma vez que expande as discussões para diferentes setores de atividades presente no ICO2/B3 e porquanto, na maioria das pesquisas relacionadas com o tema, os resultados foram limitados a setores específicos, a exemplo das pesquisas de Barbosa et al., (2013) e Andrade et al. (2013) - que consideram, apenas, empresas brasileiras não financeiras e Amaral (2012) - que investigou o setor minero-metalúrgico no Brasil. Além disso, a presente pesquisa traz uma abordagem metodológica ampliada, com a aplicação de diferentes modelos econométricos (regressão linear múltipla em painel combinada com regressão em painel Seemingly Unrelated Regressions - SUR, que permite individualizar os resultados de cada empresa), além de realizar estudos comparativos entre empresas participantes e não participantes do índice ICO2/B3 S.A., para verificar a existência ou não de diferenças entre grupos e analisar os resultados individuais das empresas no que se refere ao retorno e à sensibilidade das ações ao risco de mercado antes e após o ingresso no índice, diferenciando-se, portanto, dos procedimentos metodológicos e técnicas estatísticas adotadas nas pesquisas de Ziegler, Busch e Hoffmann (2011), Lourenço et. al., (2011), Teixeira, Nossa e Funchal (2011), Ziegler (2012), Andrade et al. (2013), Cruz (2015) e Gomes et. al. (2017), que apesar de terem utilizadas regressões múltiplas com dados em painel, não usaram a regressão $S U R$ para individualizar os resultados das empresas para fins de análises focalizadas.

Assim, o objetivo geral dessa pesquisa consistiu em examinar qual a relação entre a participação das empresas no ICO2/B3 (proxy) e o retorno e sensibilidade de suas ações ao risco de mercado visando subsidiar a tomada de decisão por parte de empresas e investidores. 
Para atingir o objetivo geral desenvolveu-se dois estudos, aqui denominados "a" e "b", para avaliar: a) através da aplicação de regressão linear múltipla em painel, se o grupo de empresas que ingressaram no ICO2 apresentaram alterações nos retornos das ações e na sensibilidade ao risco de mercado se comparado com o grupo de empresas que não ingressaram no ICO2; e b) mediante uso de regressão linear múltipla em painel combinada com regressão $S U R$, se o retorno das ações e a sensibilidade ao risco de mercado das empresas, após admissão na carteira teórica do ICO2, apresentaram alterações.

$\mathrm{O}$ artigo está estruturado em 5 seções, sendo a primeira a presente introdução. $\mathrm{Na}$ segunda são discutidos os aparatos teóricos utilizados para fundamentar a relação entre iniciativas empresariais em clima e desempenho econômico-financeiro. Na sequência, a terceira apresenta os procedimentos metodológicos utilizados na pesquisa. A quarta, por sua vez, discute os resultados encontrados nos estudos "a" e "b". Por fim, a quinta fecha o artigo com as conclusões e recomendações finais.

\section{INICIATIVAS EMPRESARIAIS EM CLIMA E DESEMPENHO ECONÔMICO- FINANCEIRO DAS EMPRESAS}

Nas últimas décadas as organizações vêm alterando o seu comportamento em face do aumento das pressões dos stakeholders por uma postura mais transparente, sustentável que venha refletir em resultados positivos e uma performance mais competitiva. Particularmente, os investidores, acionistas, clientes e o governo têm cobrado das organizações uma mudança de práticas em consequência dos desafios trazidos por uma conjuntura climática que traz riscos econômicos, riscos financeiros, riscos físicos, riscos reputacionais, riscos sociais, geográficos e culturais (LABATT; WHITE, 2007, IPCC, 2013; FARIAS, 2013).

O aumento de pressões por parte dos investidores nas empresas, em virtude dos riscos climáticos reflete uma preocupação e o reconhecimento de que as mudanças climáticas afetam a todos, principalmente pela explicação dos riscos cientificamente (IPCC, 2013) deixando as atividades produtivas vulneráveis e demandando estratégias e iniciativas para enfrentamento do fenômeno. Dessa forma, espera-se que a partir desse contexto as organizações aumentem o volume de informações que são divulgadas ao mercado, reduzindo, assim, a percepção do risco empresarial (FREEMAN et al., 2010; ZIEGLER, 2012; BUOSI, 2014; MISANI; POGUTZ, 2015).

Segundo Ziegler, Busch e Hoffman (2011) o reconhecimento de que as mudanças climáticas é um dos principais problemas discutidos no cenário mundial, conformados por múltiplas questões com impactos diversos na sociedade constitui um dos principais desafios no contexto global. Para as corporações, segundo as autoras, o impacto provocado pelo fenômeno vai desde as pressões regulatórias às perdas de competividade, financeira e de mercado, além de questões de reputação e de legitimidade.

Muitas pesquisas vêm buscando compreender se o desempenho corporativo tem sido afetado diante de mudanças na conjuntura ambiental e climática, seja correlacionando práticas de Responsabilidade Social Corporativa (RSC) e o desempenho econômico e financeiro, seja correlacionando o disclosure ambiental e o carbon disclosure com o desempenho financeiro, como também a participação em índice de sustentabilidade e a performance corporativa. Particularmente, as pesquisas que buscaram relacionar as questões climáticas com o desempenho econômico e financeiro das empresas, cujos primeiros estudos datam de 1972 e 1989 (FREEDMAN; JAGGI, 1992), ao longo das últimas três décadas têm evoluído, por conta da demanda de informações pelos stakeholders em face de preocupações com os riscos das mudanças climáticas.

Diante do desafio posto para as empresas pautado na configuração e na divulgação de estratégias para enfrentamento das mudanças climáticas e na participação em Iniciativas Empresariais em Clima, observa-se um movimento das organizações no sentido de ingressarem 
RETORNO DAS AÇÕES E SENSIBILIDADE AO RISCO DE MERCADO DAS EMPRESAS PARTICIPANTES DO ÍNDICE CARBONO EFICIENTE (ICO2) DA B3 S.A.: UM ESTUDO COMPARATIVO

em iniciativas de sustentabilidade, a exemplo dos índices, cujo objetivo visa à busca de melhoria da reputação, valorização das ações e redução da volatilidade de seus papéis (TEIXEIRA; NOSSA; FUNCHAL 2011; ZIEGLER; BUSCH; HOFFMANN, 2011; AMARAL, 2012; ZIEGLER, 2012; MILANI et al., 2012; ANDRADE et al., 2013).

Rezende, Nunes e Portela (2008) realizaram uma pesquisa com o objetivo de analisar a relação entre o ISE em relação aos retornos dos índices Ibovespa, IBrX e IGC. Utilizaram para tal, o Teste-T, considerando duas amostras para média. Os resultados evidenciaram que o ISE apresentou retorno semelhante aos demais índices, ou seja, não possuía desempenho superior por levar em consideração as práticas de sustentabilidade se comparado aos demais.

Seguindo esses achados, Cavalcante, Bruni e Costa (2009) realizaram uma pesquisa com o intuito de comparar a performance das ações de empresas pertencentes a uma carteira teórica do ISE com a performance de ações das organizações que formavam as carteiras teóricas do Ibovespa e do IBrX. Para tanto, compararam-se os retornos e o desvio padrão dos três índices, além de testes de estacionariedade. Os resultados obtidos indicaram que, no período após a criação do ISE, não se observou uma performance superior ao ser comparada com o Ibovespa e o IBrX, sendo que o primeiro apresentou uma variação maior do que os demais. Observouse, por outro lado, que o ISE se mostrou superior no período que antecede a sua criação, indicando que a precificação ocorreu antes de sua divulgação.

O estudo de Ziegler, Busch e Hoffmann (2011) buscou analisar a relação entre as respostas empresariais às mudanças climáticas e o retorno das ações de empresas nos mercados de ações na Europa e nos Estados Unidos da América (EUA) (exceto as do setor bancário), no período de 2001 a 2006. Para tanto, realizou testes estatísticos de regressões múltiplas e utilizou, para estimar os retornos, o modelo de precificação de quatro fatores, além do CAPM - modelo considerado de um fator. Os resultados indicaram, em relação aos investidores, que a negociação de ações de empresas que adotam respostas às mudanças climáticas mostrou-se mais vantajosa se comparada com ações de empresas que não gerenciam as mudanças climáticas, sobretudo na Europa. Ainda em relação as empresas europeias, os autores verificaram haver relação positiva entre a evidenciação das respostas às mudanças climáticas e o retorno das empresas. Ademais, em relação aos EUA, a pesquisa evidenciou haver relações entre as respostas empresariais às mudanças climáticas e o desempenho financeiro, apenas, para empresas do setor de energia, o que segundo o autor pode ser fruto das pressões das pressões regulatórias e das políticas ambientais.

Lourenço et al., (2011) realizaram uma pesquisa com o objetivo de verificar se o mercado penaliza as empresas com baixo desempenho em sustentabilidade corporativa, bem como se o tamanho e a rentabilidade das empresas influenciavam nas penalizações, utilizando para tanto técnicas estatísticas de regressões múltiplas em painel. Para esse fim, analisaram uma amostra contendo empresas do Canadá e EUA, de diferentes setores, sendo a amostra classificada em dois grupos: Assim, categorizam-se as empresas em dois grupos: no primeiro, as empresas que fizeram parte do DJSI North totalizando 63 companhias (são incluídas nesse índice $20 \%$ das 600 maiores empresas do Canadá e EUA que pertenciam ao Dow Jones Global Total Stock Market Index (DJGTSM), consideradas líderes em sustentabilidade); já no segundo grupo as empresas que fizeram parte do DJGTSM, mas que não estavam no DJSI (proxy), que somavam 355 empresas, cujo período analisado foi de 2007 a 2010. Corroborando com Ziegler, Busch e Hoffmann (2011), os resultados mostraram que os investidores valorizavam as empresas que possuíam níveis de práticas de sustentabilidade corporativa superiores no mercado, tendendo a comprar ações de empresas comprometidas com a sustentabilidade.

A pesquisa de Teixeira, Nossa e Funchal (2011) visou investigar se o ISE é determinante no endividamento das empresas que dele participavam. Para tanto, analisou o período de 2003 (3 anos antes da criação do índice que foi em 2005) a 2008 (três anos após a criação do índice). O método empregado foi o de estudo de eventos, por meio de regressão com dados em painel 
André L. R. de Souza - Antônio F. A. da Silva Junior - José C. S. Andrade - Maria Eduarda S. T. Fernandes

com duplo efeito fixo. A amostra da pesquisa foi composta por 378 empresas, das quais 94 participavam do ISE no período e 284 não participavam. Os resultados indicaram que, além do ISE influenciar, estatisticamente, o endividamento das empresas, o grupo de empresas que fazia parte desse índice apresentava uma relação negativa com o endividamento em comparação com o grupo de empresas que não fazia parte do índice. Por fim, a pesquisa evidenciou que o grupo de empresas que pertenciam ao ISE apresentava uma redução do beta (risco) se comparado com o grupo de empesas que não pertencia a esse índice.

Corroborando a pesquisa de Teixeira, Nossa e Funchal (2011), a investigação realizada por Milani et al. (2012) buscou analisar se a aplicação de recursos em organizações com boas práticas de Sustentabilidade, RSC e Governança Corporativa apresentavam performance superior quando comparados com investimentos em organizações representativas do mercado. Para tanto utilizaram uma abordagem quantitativa, com técnicas estatísticas e testes não paramétricos de diferenças de médias, com análise focadas na relação risco e retorno, utilizando o índice de Sharpe. Os resultados indicaram que a aplicação de recursos em organizações com melhores práticas de sustentabilidade, boas práticas de governança e RSC apresentam retornos melhores e baixa sensibilidade ao risco de mercado, apresentando menores riscos para os investidores. Por fim, observou-se ainda que as organizações que pertenciam a carteiras teóricas de índices considerados de melhores práticas (IGC e ICO2) apresentaram desempenho melhor do que o conjunto de organizações que pertenciam ao Ibovespa (carteira representativa do mercado).

Embora não seja unânime, as pesquisas de Teixeira, Nossa e Funchal (2011) e Milani et al., (2012) evidenciaram que a participação em índice de sustentabilidade contribui, dentre outras questões, para a redução da percepção do risco empresarial pelos investidores e para a redução da sensibilidade das ações ao risco de mercado, o que, segundo os autores, pode ser uma das iniciativas utilizadas para estreitar o seu relacionamento com os stakeholders.

A pesquisa realizada por Ziegler (2012) analisou se existia relação entre a admissão de empresas europeias no DJSI e sua influência no desempenho financeiro. Para tanto, considerouse o período compreendido entre 1999 e 2003, focalizando as empresas que foram incluídas no índice DJStoxx 600 e utilizou-se técnicas estatísticas de regressão com dados em painel, utilizando um modelo econométrico flexível, por meio de efeitos aleatórios e fixos. $\mathrm{O}$ desempenho financeiro foi medido pelo $Q$ de Tobin (relação entre o valor de mercado da empresa somado às dividas, dividido pelo ativo total) e o Retorno sobre o Ativo (ROA). Os resultados evidenciaram que para as empresas pertencentes ao Reino Unido e Irlanda, a inclusão das organizações no DJSI não impactou no desempenho financeiro, medido através do ROA. Contudo, para outros países da Europa, verificou-se relação positiva entre o ingresso no índice e o desempenho financeiro. De acordo com a autora, a principal diferença está na característica dos países, separados entre os países europeus Anglo-Saxões e os da Europa continental. Uma das hipóteses levantadas é a de que os stakeholders, nos países europeus Anglo-Saxões, têm uma atuação menor do que em países europeus continentais. Os resultados encontrados por Ziegler (2012) convergem com os achados das pesquisas de Rezende, Nunes e Portela (2008) e Cavalcante, Bruni e Costa (2009). Por outro lado, os resultados divergem, parcialmente, dos achados das pesquisas de Milani et al., (2012), Teixeira, Nossa e Funchal (2011), Ziegler, Busch e Hoffmann (2011) e Lourenço et al., (2011).

Em pesquisa realizada por Amaral (2012) buscou-se compreender se as iniciativas corporativas de gestão das emissões de Gases de Efeito Estufa (GEE) e as práticas de RSC geram valor para a organização, do setor mínero-metarlúrgico, na visão dos acionistas. A variável dependente do estudo foi o preço da ação e as variáveis explicativas foram os índices ISE e o ICO2 (considenrando esses índices como "vitrine" das práticas corporativas) e como meios para avaliação de ganhos reputacionais o Ibovespa e o preço do minério de ferro. Os resultados indicaram que o ingresso nos índices (ISE e ICO2) afigura-se estatisticamente 
RETORNO DAS AÇÕES E SENSIBILIDADE AO RISCO DE MERCADO DAS EMPRESAS PARTICIPANTES DO ÍNDICE CARBONO EFICIENTE (ICO2) DA B3 S.A.: UM ESTUDO COMPARATIVO

significativo para o valor das ações das empresas do setor mínero-metalúrgico brasileiro. Contudo, em relação ao ISE, os coeficientes estimadores das ações ordinária e preferenciais das empresas (VALE ON, GERD ON, GERD PN, GERDMET ON e GERDMET PN) foram positivos. Já em relação ao ICO2, o coefientes das ações ordinárias da Vale foi positivo enquanto que o coeficiente das ações ordinárias da MMX foi negativo. Nesse sentido, verificouse que o ISE contribui para a geração de valor das ações das empresas, enquanto, no ICO2 não foi possível verificar qual seria o efeito sobre o valor das ações em face dos achados (negativos e positivos). Já em relação ao preço do minero de ferro não observou-se significância estatística.

A pesquisa de Andrade et al. (2013) investigou as motivações que levaram as empresas a aderirem ao ISE e se existia relação entre a participação das empresas nesse índice e o seu valor, medido pelo desempenho financeiro da empresa, cujo corte temporal foi de 2006 a 2011. A amostra foi composta por dois subgrupos: um formado pelas empresas pertencentes ao ISE e o outro composto por empresas que pertenciam ao IBOVESPA, mas que não estavam no ISE, classificando-as de acordo com o setor de alto ou moderado impacto ao meio ambiente. A amostra foi composta por empresas não financeiras. Para tanto, utilizaram-se técnicas estatísticas de regressão logística (modelo logit), aplicando a análise em painel. Os resultados mostraram que os setores de atuação da empresa, bem como o tamanho e o grau de impacto ao meio ambiente são determinantes para adesão aos índices de sustentabilidade. Os achados indicaram também que em 2008, ano da crise, observou-se presença de relação positiva entre o ISE e o valor das empresas, como também se verificou que as empresas que estavam no ISE tiveram uma perda menor no valor das ações quando comparadas com as empresas que não estavam neste índice, sugerindo que as empresas que aderem a estas iniciativas estão propensas a um menor risco sistemático.

A pesquisa de Barbosa et al. (2013) teve por objetivo verificar se os retornos das ações das empresas pertencentes ao ICO2 foram afetados após a divulgação de participação na carteira teórica do índice, utilizando para tanto técnicas estatísticas, por meio de estudos de eventos. Os autores trabalharam com uma amostra de 28 empresas que formaram a primeira carteira do ICO2, em 2010, excluindo-se as empresas financeiras da amostra. Utilizaram, para tanto, a abordagem de estudo de eventos. Os resultados encontrados indicaram que a divulgação da participação no ICO2 não impactou no retorno das ações dessas empresas. A pesquisa se limitou a analisar empresas não financeiras de capital aberto presentes na carteira teórica do ICO2.

O estudo de Buosi (2014) centrou-se em analisar a existência de relação entre a gestão de emissões de GEE e o desempenho financeiro de organizações de capital aberto no Brasil, pertencentes ao ICO2, no período de 2009 a 2012. Para tanto, o autor utilizou técnicas estatísticas de regressão por MQO. Os resultados evidenciaram haver uma fraca relação, negativa, entre a eficiência de carbono das empresas, medida pelo coeficiente de emissão/receita do ICO2 e o ROS-Retorno sobre vendas.

Já a pesquisa de Cruz (2015), cujo objetivo foi verificar a relação entre o disclosure de informações corporativas relacionadas às mudanças climáticas e a performance econômicofinanceira de companhias participantes do ISE, no período compreendido entre 2011 a 2014. Para tanto, utilizou-se técnicas estatísticas de regressão em painel. Os resultados evidenciaram não haver relação estatisticamente significativa entre a evidenciação das respostas empresariais às mudanças climáticas e o desempenho econômico-financeiro das empresas listadas no ISE/B3.

A pesquisa realizada por Gomes et. al. (2017) examinou a relação entre a evidenciação dos riscos decorrentes das mudanças climáticas e o valor das ações de empresas listadas na B3. S.A. no ano de 2012. Para tanto, os autores utilizaram técnicas estatísticas de regressão multivariada para verificar se a evidenciação impactava ou não sobre o retorno anormal das 
ações. Os resultados não evidenciaram haver relação entre as variáveis (disclosure dos riscos oriundos das mudanças climáticas e o valor das ações).

Silva, Araújo e Santos (2018), visando examinar qual a relação entre o retorno e a evidenciação de provisões e passivos ambientais de empresas classificadas no setor de alto impacto de poluição, conforme a Lei $N^{\circ} 10.165 / 2000$, e listadas na B3, com ações negociadas entre os períodos de 2011 a 2016, utilizaram uma abordagem qualitativa por meio da análise de conteúdo das evidenciações das corporações, bem como técnica estatística de regressão múltipla com dados em painel e chegaram aos seguintes resultados: a) as práticas de disclosure não necessariamente estão relacionadas com as empresas mais rentáveis, pois apesar de existir relação entre rentabilidade e evidenciação de provisões e passivos ambientais, não se observou uma maior evidenciação por parte das empresas que apresentavam maior rentabilidade; b) existência de uma relação negativa entre a participação no ISE e disclosure de informações relacionadas a provisões e passivos ambientais, sugerindo uma tendência de baixa evidenciação ambiental por parte das empresas estudadas; c) as empresas com mais endividamentos tendem a divulgar mais provisões e passivos ambientais.

As pesquisas Rezende, Nunes e Portela (2008), Cavalcante, Bruni e Costa (2009), Ziegler (2012), Barbosa et al., (2013) evidenciaram não haver diferenças no desempenho financeiro de organizações que aderem às iniciativas de sustentabilidade, a exemplo dos índices, e organizações que não aderem, bem como que participar de índices de sustentabilidade não impacta no desempenho econômico-financeiro. Diferentemente destas, os estudos de Ziegler, Busch e Hoffmann (2011), Lourenço et al., (2011), Teixeira, Nossa e Funchal (2011), Milani et al., (2012), Amaral (2012) e Andrade et al., (2013) evidenciam haver diferenças positivas entre os desempenhos de corporações pertencentes à índices de sustentabilidade e organizações que não pertencem a tais iniciativas. Ademais, nas pesquisas de Teixeira, Nossa e Funchal (2011), Milani et al., (2012) e Andrade et al. (2013) verificaram-se que as empresas participantes de índices de sustentabilidade apresentaram menor sensibilidade ao risco de mercado do que as empresas que não ingressaram nos índices, o que pode atrair a atenção de investidores preocupados em alocar recursos em empresas com melhores práticas de sustentabilidade.

Contudo, não se pode afirmar que tais diferenças é fruto, exclusivamente, do ingresso nessas iniciativas, já que as práticas de gestão têm papel fundamental e direto na performance corporativa, conforme afirmam Al-Tuwaijri, Christensen e Hughes (2004) e Lemme (2010). Esses diferentes resultados reforçam a importância da presente pesquisa e a necessidade de continuidade das pesquisas que investigam a relação entre a gestão da sustentabilidade, medida pelos índices de sustentabilidade e outros indicadores e o desempenho financeiro das organizações, através de testes de modelos e variáveis diferentes dos que já foram utilizados, além da ampliação dos horizontes temporais. Ademais, é importante aprofundar as discussões teóricas-empíricas em face das divergências dos resultados encontradas e discutidos anteriormente e da necessidade de subsidiar informações para as decisões de investimentos dos investidores. pesquisa.

A seguir, apresentam-se os caminhos percorridos para a operacionalização desta

\section{PROCEDIMENTOS METODOLÓGICOS}

Para a operacionalização da presente pesquisa adotou-se uma abordagem quantitativa e descritiva, para a qual foram utilizadas técnicas estatísticas de regressão linear múltipla, cujos dados secundários foram coletados por meio da base de dados Economática. Em complemento, realizou-se uma pesquisa bibliográfica (a partir de referências que compõe o estado da arte na área) e documental (que demandam uma análise do investigador e complementam as pesquisas bibliográficas), por meio da consulta a teses, dissertações, livros e artigos científicos publicados 
RETORNO DAS AÇÕES E SENSIBILIDADE AO RISCO DE MERCADO DAS EMPRESAS PARTICIPANTES DO ÍNDICE CARBONO EFICIENTE (ICO2) DA B3 S.A.: UM ESTUDO COMPARATIVO

em âmbito nacional e internacional, além de consultas em relatórios técnicos e a sites institucionais (CORREIA; MESQUITA, 2014; ALBARELLO et al., 2011).

Destarte, a investigação por meio da pesquisa quantitativa, empregando para tanto técnicas estatísticas, visa compreender, através dos números, os comportamentos de determinados fenômenos, bem como, as relações ou não existentes entre a variável dependente e duas ou mais variáveis independentes, contribuindo para a análise das relações de causa e efeito (RODRIGUES; PAULO, 2012; ALBARELLO, al., 2011; MARCONI; LAKATOS, 2011; FERREIRA; SARMENTO, 2009).

Visando alcançar os objetivos desta pesquisa, os procedimentos metodológicos adotados passaram pela definição da unidade de análise, estratégia metodológica, corte temporal, amostra da pesquisa, hipóteses, modelo da regressão e variáveis de análises, conforme discutido na sequência.

\subsection{Unidade de Análise}

A unidade de análise consiste no Índice Carbono Eficiente (ICO2) da B3 S.A. O ICO2, índice de mercado, criado em 2010, a partir da iniciativa entre a B3 S.A. e o Banco Nacional de Desenvolvimento Econômico e Social (BNDES). O objetivo do índice constitui mensurar a eficiência em carbono das empresas. Esse índice mede quanto de emissão foi necessária para geração do faturamento de uma empresa, ou, mais especificamente, quanto de emissão de GEE, em tCO2e, foi necessário para cada $\mathrm{R} \$ 1$ (um) real de faturamento. Essa iniciativa é formada por organizações que pertencem ao Índice Brasil 50 (IBrX-50) (composto pelas 50 ações mais negociadas na B3, ponderadas na carteira pelo free float (quantidade de ações da empresa disponíveis para negociação no mercado) que, ao serem convidadas aceitaram participar do ICO2, devendo para tanto adotar práticas de gestão das emissões de GEE (BM\&FBOVESPA, 2014a, 2014b, 2015a, 2015b; B3, 2018a).

O ICO2 é um índice específico para companhias pertencentes a B3 e apresenta metodologia com exigências específicas, tais como o reporte de emissões dos escopos 1 e 2 e emissões do escopo 3 relativas a viagens aéreas a negócios, transporte e distribuição (BM\&FBOVESPA, 2013). Para tanto, possui um instrumento de coleta de dados específico e uma metodologia que induz a elaboração e publicação dos inventários de emissões pelas empresas, além de contemplar as emissões de empresas com sede no Brasil e no exterior. Destaca-se que o nível de eficiência das emissões de GEE e o free float dos papéis são fatores de ponderação das ações das companhias participantes da carteira do ICO2 (B3, 2018a).

\subsection{Estratégia Metodológica, Corte Temporal e Amostras da Pesquisa}

A estratégia metodológica empregada nessa pesquisa foi dividida em dois estudos denominados de estudos "a" e "b". O estudo "a" avalia o retorno e o risco sistemático de empresas que fazem parte do ICO2 e de empresas que não fazem parte do índice. O estudo " $b$ " investiga o retorno e o risco sistemático de empresas antes e depois de ingressarem no índice. Os dados secundários foram compostos pela cotação mensal dos preços das ações das empresas que foram utilizadas para cálculo do retorno dos papéis, bem como os pontos mensais do Ibovespa que foram utilizados para cálculo dos retornos da carteira de mercado. A fonte de extração dos dados foi a base de dados Economática, a qual dispõe de um conjunto de informações robustas sobre a performance econômico-financeira das companhias (SILVA; ARAÚJO; SANTOS, 2018). Em relação ao Ibovespa, Milani et al. (2012) e Oliveira e Pacheco (2017) destacam que consiste no principal índice do mercado de ações no Brasil e reflete a performance da carteira de mercado composta pelas principais ações negociadas na B3. Segundo Milani et al. (2012, p. 672) "[...] o Ibovespa é comumente utilizado como benchmark do mercado brasileiro". 
Cabe destacar que os dados mensais foram considerados nessa pesquisa, pois deram mais segurança, ao serem comparados com os dados diários em face dos possíveis efeitos de eventos que impactam a cotação dos papéis diariamente. Isso porque os preços das ações podem apresentar maior sensibilidade aos fenômenos diários que podem afetar a negociação dos papéis das empresas em determinadas datas, a exemplo de eventos divulgados pelas empresas e/ou fatos decorrente de questões econômicas que podem afetar a empresa, baixa negociabilidade e/ou falta de negociações na Bolsa (NEVES, 2002). Em relação à questão de baixa negociabilidade e/ou falta de negociações na bolsa, o fato de as empresas terem pertencido ao IBrX-50, dentre as mais negociadas e liquida do mercado, reduziu esse risco (CAMARGOS; BARBOSA, 2003; NEVES, 2002).

Cabe destacar que os dados foram organizados em painel, em decorrência do número de empresas da amostra de cada estudo, o que permite aumentar a robustez da base de dados, melhorar a qualidade informacional de estimação e das análises. Segundo Dantas et al. (2006) esse procedimento leva em consideração as variáveis em seus aspectos no tempo e no espaço. O Quadro 1 detalha a estratégia metodológica da pesquisa.

Quadro 1- Estratégia Metodológica, estudos e corte temporal

\begin{tabular}{|c|c|c|c|}
\hline Estratégia & Estudos & Corte Temporal & $\begin{array}{c}\text { Objetivo } \\
\text { Específico } \\
\text { Alcançado }\end{array}$ \\
\hline \multirow{2}{*}{$\begin{array}{c}\text { Abordagem } \\
\text { Quantitativa } \\
\text { Estatística }\end{array}$} & $\begin{array}{l}\text { Estudo A: Estudo com regressão linear múltipla } \\
\text { pelos modelos MQO e com dados em painel, visando } \\
\text { compreender se as ações das empresas que } \\
\text { ingressaram no ICO2, a partir de janeiro de } 2011 \text {, } \\
\text { apresentaram alterações nos retornos das ações e } \\
\text { sensibilidade ao risco de mercado significativamente } \\
\text { superior se comparado com as ações das empresas } \\
\text { que não ingressaram ao ICO2, mas compuseram a } \\
\text { carteira base do índice, IBrX-50. }\end{array}$ & $\begin{array}{l}\text { Cotações das ações no } \\
\text { período de janeiro de } \\
2011 \text { a dezembro de } \\
2013 \text {, ou seja, } 36 \text { meses } \\
\text { após a vigência da } \\
\text { primeira carteira do } \\
\text { ICO2. }\end{array}$ & "a" \\
\hline & $\begin{array}{l}\text { Estudo B: Estudo com regressão linear múltipla } \\
\text { pelos modelos SUR, MQO e com dados em painel, } \\
\text { com as empresas que ingressaram no ICO2, visando } \\
\text { compreender, se o retorno e a sensibilidade ao risco } \\
\text { de mercado das ações dessas empresas apresentaram } \\
\text { alterações significativas após admissão na carteira } \\
\text { teórica do ICO2 em face ao período de pré-admissão. }\end{array}$ & $\begin{array}{l}\text { Cotações das ações } 36 \\
\text { meses antes da data da } \\
\text { divulgação } \\
\text { lançamento do ICO2 em } \\
02 / 12 / 2010(02 / 12 / 2007) \\
\text { e } 36 \text { meses após a } \\
\text { divulgação do evento, ou } \\
\text { seja, 02/12/2013. }\end{array}$ & "b" \\
\hline
\end{tabular}

Fonte: Elaborado pelos autores.

\subsubsection{Amostra do estudo " $a$ "}

Em relação ao estudo "a", as ações das empresas que compuseram a amostra foram aquelas que, ao iniciarem na carteira teórica do ICO2 em janeiro de 2011 (44 papéis e 42 empresas), se mantiveram no índice até dezembro de 2013 (27). Isso se deve ao fato de que muitas saíram do ICO2, por não reportaram dados das suas emissões nos quadrimestres seguintes ou porque foram excluídas do $\mathrm{IBrX}-50$, ou por uma decisão da própria empresa, o que poderia interferir nos dados utilizados dos preços das ações na regressão.

Assim, as empresas do estudo "a", conforme Figura 1 (subcírculo branco), totalizaram 27 empresas. Para a comparação do estudo foram usadas 8 empresas (identificadas na Figura 1 como “Empresas IBrX-50, não ICO2") que se mantiveram no IBrX-50 durante todo o período, mas que não ingressaram no ICO2. No IBrX-50 existiam 48 empresas, das quais 27 ingressaram no ICO2, 13 não atenderam ao critério definido nesta pesquisa de terem permanecido no IBrX50 durante o período de análise, como também não estavam no $\mathrm{ICO} 2$, ficando apenas 8 empresas que foram usadas para fins de comparação. 

PARTICIPANTES DO ÍNDICE CARBONO EFICIENTE (ICO2) DA B3 S.A.: UM ESTUDO COMPARATIVO

Nesse sentido, a estratégia utilizada para comparação dos dois grupos de ações das empresas é apresentada na Figura 1.

Figura 1 - Estratégia para definição da amostra do estudo "a"

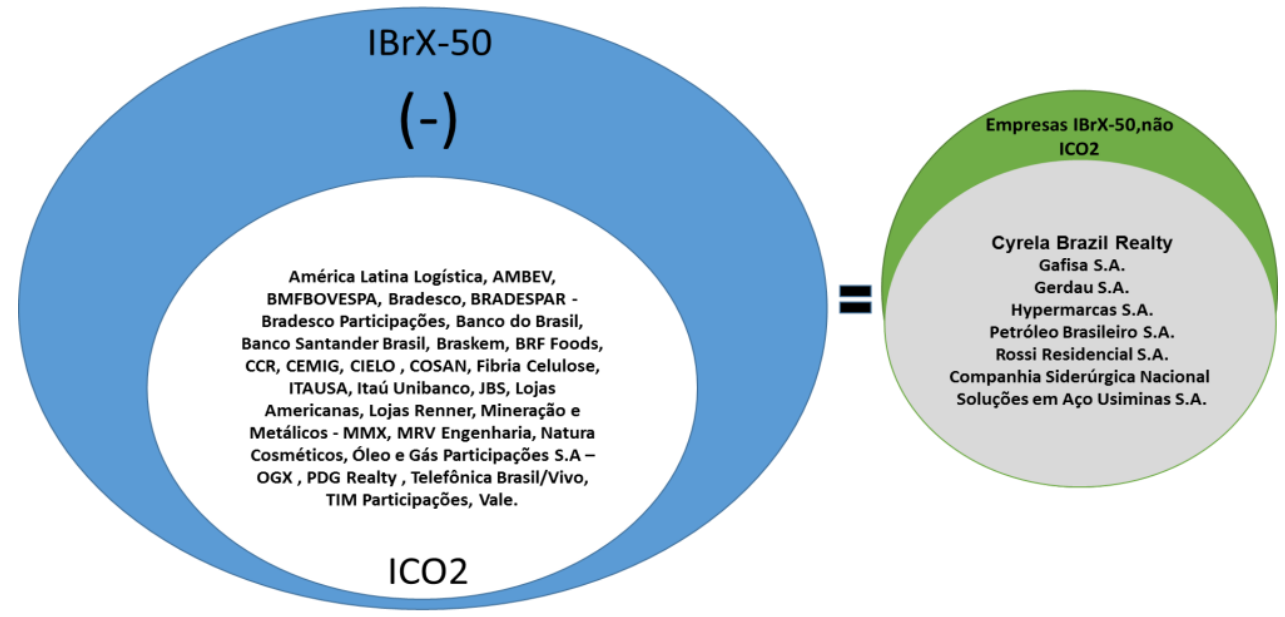

Fonte: Elaborado pelos autores.

\subsubsection{Amostra do Estudo "b"}

Com relação ao estudo "b", as ações (28 papéis) das empresas que fizeram parte do presente estudo foram aquelas que ingressaram na primeira carteira teórica do ICO2 (2011) e permaneceram neste índice durante todo o período de análise da pesquisa, totalizando 27 empresas (sendo que a Vale participava com 2 papéis), sem que tenham sido excluídas em algum dos quadrimestres correspondentes ao período definido.

A amostra do estudo " $b$ " foi composta pelas ações das empresas do Quadro 2:

Quadro 2 - Amostra estudo "b"

\begin{tabular}{|c|c|c|c|c|}
\hline Empresas/Papéis & Empresas/Papéis & Empresas/Papéis & Empresas/Papéis & Empresas/Papéis \\
\hline $\begin{array}{l}\text { América Latina } \\
\text { Logística (ALLL3) }\end{array}$ & $\begin{array}{l}\text { Banco Santander } \\
\text { Brasil S.A. } \\
\text { (SANB11) }\end{array}$ & $\begin{array}{c}\text { Cosan S.A. } \\
\text { Indústria e } \\
\text { Comércio }(\mathrm{CSAN} 3)\end{array}$ & $\begin{array}{l}\text { Lojas Renner S.A. } \\
\text { (LREN3) }\end{array}$ & $\begin{array}{l}\text { Telefônica } \\
\text { Brasil/VIVO } \\
\text { (VIVO4) }\end{array}$ \\
\hline $\begin{array}{c}\text { Companhia de } \\
\text { Bebidas das } \\
\text { Américas (AMBV4) }\end{array}$ & $\begin{array}{l}\text { Braskem S.A. } \\
\text { (BRKM5) }\end{array}$ & $\begin{array}{l}\text { Fibria Celulose } \\
\text { S.A. (FIBR3) }\end{array}$ & $\begin{array}{l}\text { Mineração e } \\
\text { Metálicos S.A. } \\
\text { (MMXM3) }\end{array}$ & $\begin{array}{c}\text { TIM } \\
\text { Participações S.A. } \\
\text { (TCSL4) } \\
\end{array}$ \\
\hline $\begin{array}{c}\text { B3 } \\
\text { (BM\&FBOVESPA) } \\
\text { B3SA3 (BVMF3)* }\end{array}$ & BRF S.A. (BRFS3) & $\begin{array}{l}\text { Investimentos Itaú } \\
\text { S.A. (ITSA4) }\end{array}$ & $\begin{array}{l}\text { MRV Engenharia } \\
\text { S.A. (MRVE3) }\end{array}$ & $\begin{array}{l}\text { Vale S.A. } \\
\text { (VALE3 e } \\
\text { VALE5) }\end{array}$ \\
\hline $\begin{array}{c}\text { Banco Bradesco S.A. } \\
\text { (BBDC4) }\end{array}$ & $\begin{array}{l}\text { Companhia de } \\
\text { Concessões } \\
\text { Rodoviárias } \\
\text { (CCRO3) } \\
\end{array}$ & $\begin{array}{c}\text { Itaú Unibanco S.A. } \\
\text { (ITUB4) }\end{array}$ & $\begin{array}{c}\text { Natura } \\
\text { Cosméticos S.A } \\
\text { (NATU3) }\end{array}$ & - \\
\hline $\begin{array}{c}\text { Bradesco } \\
\text { Participações S.A. } \\
\text { (BRAP4) }\end{array}$ & $\begin{array}{c}\text { Companhia } \\
\text { Energética de } \\
\text { Minas Gerais } \\
(\mathrm{CMIG} 4)\end{array}$ & JBS S.A. (JBSS3) & $\begin{array}{c}\text { Óleo e Gás } \\
\text { Participações S.A } \\
\text { - OGX (OGXP3) }\end{array}$ & - \\
\hline $\begin{array}{c}\text { Banco do Brasil S.A. } \\
\text { (BBAS3) }\end{array}$ & $\begin{array}{l}\text { CIELO S.A. } \\
\text { (CIEL3) }\end{array}$ & $\begin{array}{l}\text { Lojas Americanas } \\
\text { S.A. (LAME4) }\end{array}$ & $\begin{array}{l}\text { PDG Realty S.A } \\
\text { (PDGR3) }\end{array}$ & - \\
\hline
\end{tabular}

*A partir de março de 2018 a B3 (Antiga BM\&FBOVESPA) modificou o ticker de BVMF3 (vigente e utilizado na época da coleta dos dados da pesquisa) para B3SA3, em função da fusão entre a BM\&FBOVESPA e a Cetip que resultou na B3.

Fonte: Elaborado pelos autores. 


\subsubsection{Hipóteses, variáveis e parâmetros do modelo de regressão - estudo " $a$ "}

Em relação ao estudo "a", a hipótese é de que as ações das empresas participantes do ICO2 obtiveram retornos superiores e riscos sistemáticos inferiores se comparado com empresas que não participavam, já que se espera que os investidores - sensíveis à temática busquem realizar seus investimentos em empresas que adotam práticas de sustentabilidade e adotem uma política de transparência, visando reduzir os riscos decorrentes das questões ambientais e das mudanças climáticas (CRUZ, 2015; AMARAL, 2012; ZIEGLER; BUSCH; HOFFMANN, 2011; ZIEGLER, 2012; KOLK; PINKSE, 2007). Nesse sentido, as hipóteses definidas para o Estudo "a" e baseadas em estudos anteriores estão apresentadas no Quadro 3.

Quadro 3 -Hipóteses do estudo "a"

\begin{tabular}{|c|c|c|}
\hline \multicolumn{2}{|c|}{ Hipóteses } & Estudos anteriores \\
\hline $\mathrm{H}_{1}$ & $\begin{array}{l}\text { H10: Não há diferença entre os retornos das ações das } \\
\text { empresas que ingressaram no ICO2 e os retornos das } \\
\text { empresas que não ingressaram nesse índice. } \\
\text { H11: Os retornos das ações das empresas que } \text { ingressaram no ICO2 são superiores aos das } \\
\text { empresas que não ingressaram nesse índice. }\end{array}$ & $\begin{array}{l}\text { Andrade et. al. (2013); Ziegler, Busch e } \\
\text { Hoffmann (2011); Lourenço et al., (2011); } \\
\text { Teixeira, Nossa e Funchal (2011); Rezende, } \\
\text { Nunes e Portela (2008); Cavalcante, Bruni e } \\
\text { Costa (2009). }\end{array}$ \\
\hline $\mathrm{H}_{2}$ & $\begin{array}{l}\text { H20: Não há diferença entre a sensibilidade ao risco } \\
\text { de mercado das ações de empresas que ingressaram } \\
\text { no ICO } 2 \text { e a sensibilidade das empresas que não } \\
\text { ingressaram nesse índice. } \\
\text { H21: A sensibilidade ao risco de mercado das ações } \\
\text { das empresas que ingressaram no ICO2 é menor do } \\
\text { que a sensibilidade das empresas que não } \\
\text { ingressaram nesse índice. }\end{array}$ & $\begin{array}{l}\text { Teixeira, Nossa e Funchal (2011); Milani et al., } \\
\text { (2012); Andrade et al. (2013). }\end{array}$ \\
\hline
\end{tabular}

Fonte: Elaborado pelos autores. Equação1:

Para testar estas hipóteses, foi desenvolvido o modelo de regressão apresentado na

$$
R_{i t}=\beta_{0}+\beta_{1} \times I C O 2+\beta_{2} \times R m_{t}+\beta_{3} I C O 2 \times R m_{t}+\varepsilon_{i t}
$$

O Quadro 4 apresenta uma descrição das variáveis e parâmetros do modelo.

Quadro 4 - Descrição das variáveis da equação do estudo "a"

\begin{tabular}{|c|l|}
\hline \multicolumn{1}{|c|}{ Sigla } & \multicolumn{1}{c|}{ Descrição } \\
\hline$R_{i t}=\left(R_{i}-R_{f}\right)$ & $\begin{array}{l}\text { Retorno da ação da empresa i, menos o retorno do ativo livre de risco, no período t. } \\
\text { (Dependente) }\end{array}$ \\
\hline$R m_{t}=\left(R_{m}-R_{f}\right)$ & $\begin{array}{l}\text { Retorno do Mercado no período t menos o retorno do ativo livre de risco } \\
\text { (Independente). Utilizou-se o retorno do Índice da Bolsa de Valores de São Paulo } \\
\text { (Ibovespa) como representativo da carteira de mercado. }\end{array}$ \\
\hline$\beta_{0}$ & Parâmetro Constante a estimar \\
\hline$\beta_{1}$ & $\begin{array}{l}\text { Coeficiente a estimar, que mede a alteração da sensibilidade do retorno da ação da } \\
\text { empresa i admitida no Îndice Carbono Eficiente (ICO2). }\end{array}$ \\
\hline$\beta_{2}$ & $\begin{array}{l}\text { Coeficiente a estimar, que mede a mudança da sensibilidade ao risco de mercado da } \\
\text { ação da empresa i. }\end{array}$ \\
\hline$\beta_{3}$ & $\begin{array}{l}\text { Coeficiente a estimar, que mede a alteração da sensibilidade ao risco de mercado da } \\
\text { ação da empresa i, admitida no Índice Carbono Eficiente (ICO2) }\end{array}$ \\
\hline ICO2 & $\begin{array}{l}\text { Variável dummy que é igual a 1 se a observação da ação da empresa i está admitida } \\
\text { no Índice Carbono Eficiente (ICO2) e 0, caso contrário. }\end{array}$ \\
\hline$\varepsilon_{i t}$ & Erro Padrão \\
\hline
\end{tabular}

Fonte: Elaborado pelos autores. 


\subsubsection{Hipóteses, variáveis e parâmetros do modelo de regressão - estudo " $b$ "}

O estudo "b" objetivou verificar se o retorno das ações e a sensibilidade ao risco de mercado das empresas após admissão na carteira teórica do ICO2 apresentaram alterações. De acordo com Batistella et al. (2004, p. 3), esse tipo de abordagem consiste em "[...] avaliar o comportamento de uma variável qualquer a partir de um evento específico. A principal ideia é calcular se o evento ocorrido gerou algum desvio no resultado esperado". Nesse sentido, as hipóteses definidas para o estudo "b" estão apresentadas no Quadro 5.

Quadro 5 - Hipóteses do estudo "b"

\begin{tabular}{|l|l|l|}
\hline \multicolumn{1}{|c|}{ Hipóteses } & \multicolumn{1}{|c|}{ Estudos Anteriores } \\
\hline $\mathrm{H}_{3}$ & $\begin{array}{l}\text { H30: Não há diferença entre os retornos das ações das } \\
\text { empresas no período de pós-admissão no ICO2 e os } \\
\text { retornos no período de pré-admissão nesse índice. } \\
\text { H31: Os retornos das ações das empresas no período } \\
\text { de pós-admissão ICO2 são diferentes dos retornos no } \\
\text { período de pré-admissão nesse índice. }\end{array}$ & $\begin{array}{l}\text { Teixeira, Nossa e Funchal (2011); Ziegler, } \\
\text { Busch e Hoffmann (2011); Amaral (2012); } \\
\text { Zigler (2012); Buosi (2014); Freedman e Jaggi } \\
\text { (1992); Zigler (2012); Barbosa et al., (2013); } \\
\text { Cruz (2015). }\end{array}$ \\
\hline $\begin{array}{l}\mathbf{H}_{40}: \text { Não há diferença entre a sensibilidade das ações } \\
\text { das empresas ao risco de mercado no período de } \\
\text { pós-admissão no ICO2 e a sensibilidade no período } \\
\text { de pré-admissão nesse índice. } \\
\text { H41:A sensibilidade das ações das empresas ao risco } \\
\text { de mercado no período de pós-admissão no ICO2 é } \\
\text { diferente da sensibilidade no período de pré- } \\
\text { admissão nesse índice. }\end{array}$ & $\begin{array}{l}\text { Teixeira, Nossa e Funchal (2011); Milani et al., } \\
\text { (2012); Andrade et al., (2013). }\end{array}$ \\
\hline
\end{tabular}

Fonte: Elaborado pelos autores.

Equação 2:

Para testar estas hipóteses, foi desenvolvido o modelo de regressão apresentado na

$$
R_{i t}=\beta_{0}+\beta_{1} D_{i t}^{p o s}+\beta_{2} R m_{t}+\beta_{3} D_{i t}^{p o s} R m_{t}+\varepsilon_{i t}
$$

O Quadro 6 apresenta uma descrição do modelo.

Quadro 6 - Descrição das variáveis da equação do estudo "b"

\begin{tabular}{|c|l|}
\hline \multicolumn{1}{|c|}{ Sigla } & \multicolumn{1}{c|}{ Descrição } \\
\hline$R_{i t}=\left(R_{i}-R_{f}\right)$ & $\begin{array}{l}\text { Retorno da Ação i, menos o retorno do ativo livre de risco, no período t. } \\
\text { (Dependente) }\end{array}$ \\
\hline$m_{t}=\left(R_{m}-R_{f}\right)$ & $\begin{array}{l}\text { Retorno do Mercado no período t menos o retorno do ativo livre de risco } \\
\text { (Independente). Utilizou-se o retorno do Índice da Bolsa de Valores de São Paulo } \\
\text { (Ibovespa) como representativo da carteira de mercado. }\end{array}$ \\
\hline$\beta_{0}$ & Parâmetro Constante a estimar \\
\hline$\beta_{1}$ & $\begin{array}{l}\text { Coeficiente a estimar, que mede a alteração da sensibilidade do retorno da ação da } \\
\text { empresa i no período de pós-admissão ao Índice Carbono Eficiente (ICO2). }\end{array}$ \\
\hline$\beta_{2}$ & $\begin{array}{l}\text { Coeficiente a estimar, que mede a alteração da sensibilidade ao risco de mercado da } \\
\text { ação da empresa i. }\end{array}$ \\
\hline$\beta_{3}$ & $\begin{array}{l}\text { Coeficiente a estimar, que mede a alteração da sensibilidade ao risco de mercado da } \\
\text { ação da empresa i, no período de após admissão na carteira teórica do Índice Carbono } \\
\text { Eficiente (ICO2) }\end{array}$ \\
\hline$D_{i t}^{\text {pos }}$ & $\begin{array}{l}\text { Variável dummy que é igual a 1 se a observação da ação da empresa i, no período t, } \\
\text { refere-se ao período de pós-admissão ao Índice Carbono Eficiente (ICO2) e 0, caso } \\
\text { contrário. }\end{array}$ \\
\hline$\varepsilon_{i t}$ & \begin{tabular}{l} 
Erro Padrão \\
\hline
\end{tabular} \\
\hline
\end{tabular}

Fonte: Elaborado pelos Autores. 
Com o intuito de obter maior proximidade à distribuição normal dos retornos, conforme Camargos e Barbosa (2003), empregou-se, nos dados, o uso da fórmula logarítmica, de acordo com a Equação 3:

$$
R_{i, t}=\operatorname{Ln}\left(\frac{P_{i, t}}{P_{i,(t-1)}}\right)
$$

Onde:

$R_{i t}=$ Retorno do ativo i no mês t.

$p_{i, t}=$ preço da ação da empresa i no fechamento do mês t.

$p_{i,(t-1)}=$ preço da ação da empresa i no fechamento do mês anterior.

Por fim, para mensurar os retornos esperados das ações das empresas da amostra dos estudos "a" e "b", utilizou-se o modelo de retorno ajustado ao risco e ao mercado, de natureza econômico-financeira, conforme Sharpe (1964), definido como Capital Asset Princing Model - CAPM e discutido amplamente na área de finanças (ASSAF NETO, 2010; GITMAN, 2010; BRIGHAM; GAPENSKI; EHRHARDT, 2001). Esse modelo vem sendo adaptado para a realização de diversas pesquisa (ARAÚJO; OLIVEIRA; SILVEIRA, 2012), tais como as pesquisas de Cruz (2015), Ziegler, Busch e Hoffman (2011), Febra (2010), Cavalcante, Bruni e Costa (2009), Camargos e Barbosa (2003), MacKinlay (1997), Brown e Waner (1980), conforme Equação 4.

$$
E\left(R_{i t}\right)=R_{f}+\left[\beta_{i}\left(R_{m t}-R_{f}\right)\right]
$$

Legenda:

$\mathrm{E}\left(\mathrm{R}_{\mathrm{it}}\right)=$ Retorno Esperado de um ativo $i$

$\mathrm{Rf}=$ Retorno de uma carteira de Ativo sem risco ou de variância mínima de risco (taxa livre de risco) não correlacionada com a carteira de mercado

$\beta_{i}=$ Beta (declividade) para o ativo $i$ ou risco sistemático da B3.

$E\left(R_{m}\right)=$ Retorno esperado da carteira de mercado, calculado a partir do Índice Ibovespa

O CAPM apresenta limitações associadas aos seus postulados teóricos, por considerar que o mercado é eficiente. Ao utilizar esse modelo, pressupõe-se que as transações não incorrem em custos; que os preços dos ativos (ações) refletem as informações existentes e disponíveis no mercado; que não há possibilidade de agentes compradores e vendedores influenciarem o preço dos ativos negociados; e que há disponibilidade das mesmas informações para todos os investidores, dentre outros postulados. Contudo, o mercado de ações brasileiro apresenta características que sinalizam a existência de imperfeições (PENTEADO; FAMÁ, 2002; ARAÚJO; OLIVEIRA; SILVA, 2012).

Para aplicação do CAPM, fez-se necessária a utilização de uma taxa de retorno de um ativo livre de risco no mercado e do retorno esperado da carteira de mercado (CAMARGOS; BARBOSA, 2003; MACKINLAY, 1997; BROWN; WANER,1980). Segundo Araújo, Oliveira e Silveira (2012), no Brasil os estudos que abordam o CAPM, têm utilizado como proxy representativa da carteira de mercado o Ibovespa, enquanto que para a representação do retorno de uma carteira de ativo sem risco as proxies mais utilizadas são a taxa do Sistema Especial de Liquidação e de Custódia - SELIC (a mais utilizada como proxy da taxa de ativo livre de risco), o Certificado de Depósito Interbancário - CDI e a Poupança.

Nos estudos "a" e "b", a taxa de retorno do ativo livre de risco considerada nesta pesquisa foi a taxa SELIC, mensal, que é utilizada para remunerar as Letras Financeiras do Tesouro - LFT, ou seja, é a taxa embutida na LFT, além de ser também a taxa de juros básica 
RETORNO DAS AÇÕES E SENSIBILIDADE AO RISCO DE MERCADO DAS EMPRESAS

PARTICIPANTES DO ÍNDICE CARBONO EFICIENTE (ICO2) DA B3 S.A.: UM ESTUDO

COMPARATIVO

da economia brasileira. Os dados mensais da SELIC foram coletados diretamente da base de dados disponibilizada pelo Banco Central do Brasil (BACEN) em seu portal.

Para o estudo "a", com base nos estudos e pesquisas de Andrade et al. (2013), Ziegler (2012), Loureiro e Costa (2009), Hill, Griffiths e Judge (2006) e Holland e Xavier (2005), foram testados os seguintes modelos: Mínimos Quadrados Ordinários (MQO); modelo com Efeitos Fixos; e modelo com Efeitos Aleatórios, utilizando para tanto o software Gretl. Para a realização do estudo "b", realizou-se a regressão com dados em painel para analisar o comportamento dos dados no conjunto das empresas do ICO2, testando, também, esses modelos, para o conjunto das empresas analisadas no software Gretl, como também o modelo de regressão linear múltipla Seemingly Unrelated Regressions - SUR ou regressão aparentemente não relacionada, através do software $R$.

$\mathrm{O}$ uso dos diferentes modelos se justifica, considerando que:

(i) Em relação ao estudo "a" as empresas do ICO2 são diferentes em termos de tamanho, segmento e valor de mercado, sendo que a amostra do índice era composta de 27 empresas, enquanto a amostra que não fazia parte da iniciativa, somaram 8 empresas. Assim, usar a regressão $S U R$ não daria o suporte necessário para testar as hipóteses, já que não seria possível realizar comparações entre os alfas (retornos) e os betas (riscos) entre as empresas dos grupos;

(ii) Com relação ao estudo "b", o objetivo foi verificar se o retorno das ações e a sensibilidade ao risco de mercado das empresas após admissão no ICO2 apresentaram alterações. Além de realizar regressões em painel para análise do comportamento dos dados do grupo de empresas, assim como no estudo "a", a utilização da regressão $S U R$ ajudou na individualização dos alfas (retornos) e betas (riscos) das empresas.

Vale destacar que as motivações econométricas que levaram a adoção dos modelos discutidos anteriormente consideraram os ganhos nos resultados em decorrência das diferenças teóricas de cada modelo. Nos modelos MQO e painel, considera-se que, no tempo e na seção os resíduos não sejam correlacionados, enquanto, no modelo de regressão $S U R$, admite-se a possibilidade de correlação na seção, além da possibilidade de individualização dos alfas e betas das empresas analisadas (HILL; GRIFFITHS; JUDGE, 2006; HOLLAND; XAVIER, 2005; COSTA-JÚNIOR; NEVES, 2000; ZELLNER, 1962).

Considerando que a presente pesquisa tem uma amostra composta por ações de várias organizações, espera-se, por meio do modelo MQO e em Painel, que o pressuposto de ausência de autocorrelação, no tempo, seja preservado. Em relação à regressão $S U R$, acredita-se que haja um movimento comum nas unidades de análise, ou seja, admite-se a possibilidade de correlação na seção e considera-se que a informação contida nessa correlação seja útil na estimação dos parâmetros. Assim, por meio do modelo $S U R$, busca-se tirar proveito da possível correlação seccional (ANDRADE et al., 2013; HILL; GRIFFITHS; JUDGE, 2006; HOLLAND; XAVIER, 2005; COSTA-JÚNIOR; NEVES, 2000; ZELLNER, 1962).

Para a verificação do modelo mais adequado das regressões em painel, realizou-se a análise da variação dos resíduos e os testes de Hausman (indicado para verificar que melhor modelo utilizar entre os estimadores de Efeitos Fixos ou Efeitos Aleatórios) e LM de BreuschPagan (voltado para analisar possíveis efeitos não identificados) (HILL; GRIFFITHS; JUDGE, 2006; DANTAS et al., 2006; HOLLAND; XAVIER, 2005). Tanto no estudo "a" quanto no estudo "b" nas análises utilizou-se, como parâmetro, para indicar uma diferença estatisticamente significativa, o p-valor menor do que 0,05 , cujo intervalo de confiança foi de $95 \%$. 


\section{APRESENTAÇÃO E ANÁLISE DOS RESULTADOS}

\subsection{Estudo " $a$ "}

Em relação ao estudo "a", as hipóteses testadas foram as definidas o Quadro 3, apresentadas anteriormente. Para tanto, procedeu-se a três regressões em painel, utilizando, para tanto, os modelos de Efeitos Fixos, Efeitos Aleatórios e o MQO. As regressões foram feitas para comparar o grupo de empresas do ICO2 com o grupo de empresas não ICO2, levando em consideração um mesmo horizonte temporal (2011 a 2013).

Para a verificação da adequação das análises, a partir dos estimadores de Efeitos Aleatórios e Efeitos Fixos, realizaram-se os diagnósticos de painel, assumindo um painel equilibrado, considerando que as séries temporais das diferentes empresas são apresentadas para um mesmo período. Para tanto foram realizados os testes de Hausman e Breusch-Pagan (HOLLAND; XAVIER, 2005; HILL; GRIFFITHS; JUDGE, 2006).

Antes de proceder aos testes de Hausman e Breusch-Pagan realizou-se a análise da variância dos resíduos. O Valores $\mathrm{F}$ foi de 2,9798, cuja variância dos resíduos foi de "0,00744397" e o p-valor foi de "1,09768e-008". Um p-valor baixo contraria a hipótese nula de que o modelo MQO agrupado (pooled) é adequado, validando a hipótese alternativa da existência de efeitos fixos.

Por outro lado, ao realizar o teste de Hausman, os resultados evidenciaram o " $\mathrm{H}$ " igual a "0" e o p-valor igual a "1". Nesse teste, um p-valor baixo contraria a hipótese nula de que o modelo de efeitos aleatórios é consistente, validando a hipótese alternativa da existência do modelo de efeitos fixos. O teste de Hausman confirmou a melhor adequação do modelo de Efeitos Aleatórios em relação ao modelo de Efeitos Fixos. Segundo Andrade et al. (2013), quando a hipótese nula não é rejeitada no teste de Hausman " "[...] indica que não existe relação entre a heterogeneidade não observada $\left(\mathrm{u}_{\mathrm{i}}\right) \mathrm{e}$ os regresores e que, por isso, o modelo de efeitos aleatórios é considerado o mais adequado, quando comparado com o modelo de efeitos fixos (p. 202).

Tabela 1 -Regressão em Painel com o modelo de Efeitos Aleatórios, no período de 2007 a 2013

\begin{tabular}{|c|c|c|}
\hline ariáveis & Modelo Adequado & Modelo Efeitos Aleatórios \\
\hline$\beta_{0}$ (Intercepto) Estimado & & $-0,00397385$ \\
\hline Erro Padrão & & 0,00735255 \\
\hline Estatística t & & $-0,5405$ \\
\hline$P$-Valor & & 0,5889 \\
\hline Dummy_ICO2 & & 0,00508169 \\
\hline Erro Padrão & & 0,00845201 \\
\hline Estatística t & & 0,6012 \\
\hline$P$-Valor & & 0,5478 \\
\hline $\mathbf{R m}$ & & 1,38336 \\
\hline Erro Padrão & & 0,0822582 \\
\hline Estatística t & & 16,82 \\
\hline$P$-Valor & & $5,35 \mathrm{e}-059 * * *$ \\
\hline Rm*DummyICO2 & & $-0,560546$ \\
\hline Erro Padrão & & 0,0945586 \\
\hline Estatística t & & $-5,928$ \\
\hline$P$-Valor & & $3,68 \mathrm{e}-09 * * *$ \\
\hline
\end{tabular}

Fonte: Dados da pesquisa.

Para confirmação desse modelo como o mais adequado ao modelo proposto na pesquisa, realizou-se o teste de Breusch-Pagan, por meio do qual os resultados indicaram um LM igual a "60,6681” e o p-valo igual a "6,75574e-015". Nesse teste, um p-valor baixo contraria a hipótese 
RETORNO DAS AÇÕES E SENSIBILIDADE AO RISCO DE MERCADO DAS EMPRESAS PARTICIPANTES DO ÍNDICE CARBONO EFICIENTE (ICO2) DA B3 S.A.: UM ESTUDO COMPARATIVO

nula de que o modelo MQO agrupado (pooled) é adequado, validando a hipótese alternativa da existência de efeitos aleatórios. Assim, verificou-se a ratificação do modelo de Efeitos Aleatórios como mais adequado para a analisar os dados do presente estudo, cujos resultados estão apresentados na Tabela 1.

Conforme pode ser observado na Tabela 1, os resultados indicaram, segundo o coeficiente $\beta_{1}$, que, para o grupo das 27 empresas admitidas no ICO2, o alfa foi igual a zero, ou seja, não apresentou alteração, cujo p-valor foi de 0,5478 . Ou seja, não há diferença para os alfas do CAPM (retornos idiossincráticos), entre os grupos de empresas que participou e que não participou do ICO2.

Diante dos achados no tocante aos retornos, verificou-se que, em relação à hipótese $\mathrm{H}_{1}$, a hipótese nula $\left(\mathrm{H}_{10}\right)$ não foi rejeitada, já que, para o grupo de 27 empresas, admitidas no ICO2, não se verificaram retornos superiores das ações quando comparadas com o grupo de 8 empresas do IBrX-50, que não estavam admitidas no ICO2, rejeitando-se, portanto, a hipótese alternativa $\left(\mathrm{H}_{11}\right)$. Esses resultados divergem dos resultados encontrados pelas pesquisas de Ziegler, Busch e Hoffmann (2011), Lourenço et al., (2011), Teixeira, Nossa e Funchal (2011), Milani et al., (2012) e Andrade et al. (2013). Os achados, por outro lado, convergiram com a pesquisa de Rezende, Nunes e Portela (2008) e Cavalcante, Bruni e Costa (2009) e Cruz (2015) que não encontraram superioridade no desempenho dos papéis que compuseram a carteira de índice de sustentabilidade em relação aos demais.

Esse resultado, guardado as particularidades, contesta os argumentos de que as empresas que participam de índices de sustentabilidade possuem desempenho superior se comparado com as empresas que não participam dessas iniciativas, estando a valorização das ações associadas a outros fatores, como as práticas de gestão, governança corporativa, os fundamentos econômico-financeiros, dentre outros. Essa perspectiva condizente com o que afirma AlTuwaijri, Christensen e Hughes (2004) e Lemme (2010), ao defenderem que um bom desempenho ambiental e desempenho econômico-financeiro estão relacionados, também, com a qualidade da gestão corporativa e conforme Gomes et al. (2017), que em seus estudos identificaram haver relação positiva entre as práticas de governança corporativa e o retorno anormal das ações de empresas listadas na B3 S.A.

A análise dos investimentos em sustentabilidade, por outro lado, remete a necessidade de se analisar um horizonte de longo prazo, a partir do qual se espera que as práticas de gestão sustentável estejam efetivamente implementadas e momento em que se podem medir os efeitos dessas práticas e iniciativas implementadas pelas empresas. Nessa perspectiva, as empresas podem reduzir a sua exposição ao risco sistemático (ANDRADE et al., 2013) e apresentar menores endividamentos (TEIXEIRA; NOSSA; FUNCHAL, 2011), além de aumentar a atratividade de investimentos decorrentes de investidores que alocam recursos em empresas com boas práticas de sustentabilidade (FINEMAM; CLAKE, 1996; ZIEGLER, 2012; FARIAS, 2013).

No geral, quando analisada a variável independente retorno do mercado (Rm), observou-se que esta variável apresenta forte significância estatística, sendo que, o beta, para o conjunto das empresas que não estão no $\mathrm{ICO} 2$, é maior do que o beta das empresas que estão no índice.

Nesse sentido, em relação à hipótese $\mathrm{H}_{2}$, conforme análise do coeficiente $\beta_{3}$, verificouse, a partir dos resultados acima, que o grupo de 27 empresas admitidas no ICO2 apresentou baixa sensibilidade ao risco de mercado, quando comparadas com o grupo de 8 empresas do IBrX-50, que não ingressaram no ICO2. A alteração observada foi negativa, a um p-valor de $3,68 \mathrm{e}-09^{* * *}$, ou seja, menor do que 0,05 , demonstrando uma alteração estatisticamente significativa. Sendo assim, a hipótese alternativa $\mathrm{H}_{21}$ foi aceita.

Esses resultados corroboram com os achados das pesquisas de Teixeira, Nossa e Funchal (2011), Milani et al., (2012) e Andrade et al. (2013) e sinalizam que as empresas que adotam 
práticas de sustentabilidade possuem uma menor exposição ao risco de mercado. Ou seja, a sensibilidade ao risco de mercado é menor para o grupo de 27 empresas que ingressaram no ICO2 se comparado com as 8 empresas que não ingressaram nesse índice. Assim, a hipótese nula $\left(\mathrm{H}_{20}\right)$ foi rejeitada. Com efeito, o grupo de empresas que pertenciam à carteira teórica do ICO2 apresentaram relação negativa com o risco da carteira de mercado se comparado com o grupo de empresas que não estavam na iniciativa.

Por conseguinte, pode-se afirmar que, embora as empresas que pertenciam à carteira teórica do ICO2 não apresentaram retornos superiores quando comparadas com o grupo de empresas que não pertenciam ao índice, verificou-se que a sensibilidade das ações das empresas ao risco de mercado é menor quando comparado com o segundo grupo, apresentando uma relação negativa. Sendo assim, pode-se afirmar, corroborando com os achados de Milani et al. (2012) e Andrade et al. (2013), que a realização de investimentos em organizações com práticas de sustentabilidade pode oferecer menores riscos quando se compara com investimentos em carteiras de investimentos representativas do mercado.

Vale destacar que, embora as empresas que tenham sido admitidas no ICO2, se comparadas com as empresas que não tenham sido admitidas, apresentaram um menor beta. Contudo, não se pode associar que essa redução do risco seja em razão única do ingresso no ICO2, pois outros fatores como o nível de alavancagem financeira e alavancagem operacional, além da natureza cíclica das receitas e questões de ordem econômica podem afetar os betas das organizações (MANDELKER; RHEE, 1984; BRIGHAM; GAPENSKI; EHRHARDT, 2001; DANTAS et al., 2006; ASSAF NETO, 2010; GITMAN, 2010).

Destaca-se que o modelo utilizado apresentou o $\mathrm{R}^{2}$ e o $\mathrm{R}^{2}$ ajustado igual a " 0,245835 " e " 0,244558 ", respectivamente. Ou seja, esse resultado sinaliza que $24,5 \%$, aproximadamente, das variações da variável dependente (retorno das ações) podem ser explicadas pelas variáveis propostas no estudo.

\subsection{Estudo "b"}

No tocante ao estudo "b", as hipóteses testadas foram as definidas no Quadro 5, apresentadas anteriormente. Nesse estudo realizou-se, no primeiro momento, a regressão em painel, para a verificação de cada hipótese do Quadro 5 em relação ao grupo de empresas investigadas, utilizando, para tanto, os modelos de Efeitos Fixos, Efeitos Aleatórios e o MQO. Na sequência procedeu-se à análise dos alfas e betas individualizados das empresas, por meio da regressão $S U R$.

Diferentemente do estudo "a", nesta pesquisa considerou-se, apenas, as empresas que pertenciam ao ICO2, analisando, como horizonte temporal, 36 meses antes (2007) do lançamento da carteira teórica do índice (2010) e 36 meses após o lançamento (2013). Para a verificação da adequação das análises, a partir dos estimadores de Efeitos Aleatórios e Efeitos Fixos, assim como foi feito no estudo "a", realizaram-se os diagnósticos de painel, por meio dos testes de Hausman e Breusch-Pagan.

Antes de proceder aos testes de Hausman e Breusch-Pagan realizou-se a análise da variância dos resíduos, cujos resultados encontrados foram: valor F igual a 1,52471, cuja variância dos resíduos foi igual a "0,00983806” e o p-valor igual a 0,108042. Nesta análise, um p-valor baixo contraria a hipótese nula de que o modelo MQO agrupado (pooled) é adequado, validando a hipótese alternativa da existência de efeitos fixos. Através desse teste, o modelo MQO foi o mais adequado. Por outro lado, ao realizar o teste de Hauman, os resultados obtidos foram os seguintes: valor H igual a “ 0,462595 ” e o p-valor igual a “0,927029”.

Neste teste, um p-valor baixo contraria a hipótese nula de que o modelo de efeitos aleatórios é consistente, validando a hipótese alternativa da existência do modelo de efeitos fixos. Os resultados do teste de Hausman evidenciaram a melhor adequação do modelo de Efeitos Aleatórios em relação ao modelo de Efeitos Fixos. 
RETORNO DAS AÇÕES E SENSIBILIDADE AO RISCO DE MERCADO DAS EMPRESAS PARTICIPANTES DO ÍNDICE CARBONO EFICIENTE (ICO2) DA B3 S.A.: UM ESTUDO COMPARATIVO

Para confirmação desse modelo como o mais adequado ao modelo proposto na pesquisa, realizou-se o teste de Breusch-Pagan. Os resultados indicaram um LM igual a "1,07699" e o pvalor igual a "0,299371". Nesse teste, um p-valor baixo contraria a hipótese nula de que o modelo MQO agrupado (pooled) é adequado, validando a hipótese alternativa da existência de efeitos aleatórios. Diante dos resultados encontrados, verificou-se que pelo teste de BreuschPagan o MQO foi o modelo mais adequado para a analisar os dados do presente estudo. Após a execução dos modelos, a seguir a Tabela 2 apresenta os resultados da regressão em painel.

Tabela 2 - Regressão em Painel com os modelos MMQ/OLS, no período de 2011 a 2013

\begin{tabular}{|c|c|c|}
\hline Variáveis & Modelos & Modelo Método Mínimos Quadrados (MQO) \\
\hline$\beta 0$ (Intercepto) Estimado & & 0,00165003 \\
\hline Erro Padrão & & 0,00245696 \\
\hline Estatística t & & 0,6716 \\
\hline P-Valor & & $\mathbf{0 , 5 0 1 9}$ \\
\hline Dummy_Dit & & $-0,00469078$ \\
\hline Erro Padrão & & 0,00680886 \\
\hline Estatística t & & $-0,6889$ \\
\hline P-Valor & & 0,4909 \\
\hline $\mathbf{R m}$ & & $\mathbf{0 , 8 8 1 1 9 2}$ \\
\hline Erro Padrão & & 0,10931 \\
\hline Estatística t & & 8,061 \\
\hline P-Valor & & $1,27 \mathrm{e}-015 * * *$ \\
\hline Dit*Rm & & $-0,167642$ \\
\hline Erro Padrão & & 0,106679 \\
\hline Estatística t & & $-1,571$ \\
\hline P-Valor & & 0,1162 \\
\hline
\end{tabular}

Fonte: Elaborado pelo Autor a partir dos dados da pesquisa.

A partir dos resultados apresentados na Tabela 2 acima, verificou-se que a hipótese nula $\left(\mathrm{H}_{30}\right)$ não foi rejeitada, pois verificou-se que os retornos das ações das empresas da amostra do estudo "b", assim como no estudo "a", conforme $\beta_{1}$, não apresentaram alterações estatisticamente significativas, após ingresso no ICO2. Esse resultado, que rejeitou a hipótese alternativa $\left(\mathrm{H}_{31}\right)$ converge com as pesquisas de Rezende, Nunes, Portela (2008), Cavalcante, Bruni e Costa (2009), Zigler (2012), Barbosa et al., (2013) e Buosi (2014). Por outro lado, diverge dos resultados dos estudos de Teixeira, Nossa e Funchal (2011), Ziegler, Busch e Hoffmann (2011), Amaral (2012), Milani et al. (2012) e Andrade et al. (2013), pois o ingresso ao índice de sustentabilidade não adicionou valor às ações das empresas que ingressaram na iniciativa.

Por meio da Tabela 2, conforme $\beta_{3}$, pode-se afirmar que a hipótese nula $\mathrm{H}_{40}$ também não foi rejeitada, pois não apresentou alterações estatisticamente significativas, cujo p-valor foi de 0,1162 . Ou seja, maior que 0,05 , rejeitando-se, portanto, a hipótese alternativa $\left(\mathrm{H}_{41}\right)$. Assim, considerando o grupo de empresas que ingressaram no ICO2, não se pode afirmar que a sensibilidade ao risco de mercado, após ingresso no ICO2 foi alterada, embora o beta do grupo de empresas da amostra, no período pós-ingresso no índice, foi menor do que o beta do período de pré-ingresso, apresentando um valor negativo. Esse achado diverge dos resultados encontrados nos estudos de Teixeira, Nossa e Funchal (2011), Milani et al., (2012) e Andrade et al. (2013).

Quando analisados os retornos (alfa) e os riscos (beta) individuais das empresas, a partir da regressão $S U R$, observou-se que a maioria não apresentou alterações estatisticamente significativas tanto nos retornos, quanto na sensibilidade ao risco de mercado, no período em que já estavam participando do ICO2, estando alinhados, portanto, com os resultados apontados pelo modelo MQO para a regressão em painel, considerando os resultados dos grupos de 
empresas. Por outro lado, verificaram-se também algumas particularidades. Esses resultados podem ser observados na Tabela 3, apresentada na sequência.

Tabela 3 - Regressão em Painel SUR com alfas e betas individualizados, no período de 2011 a 2013

\begin{tabular}{|c|c|c|c|c|c|c|c|c|}
\hline $\begin{array}{l}\text { Empresa } \\
\text { Variável }\end{array}$ & AMBEV & $\begin{array}{l}\text { América } \\
\text { Latina } \\
\text { Logística }\end{array}$ & $\begin{array}{c}\text { Banco do } \\
\text { Brasil }\end{array}$ & $\begin{array}{c}\text { Banco } \\
\text { Bradesco }\end{array}$ & Bradespar & BRF Foods & Braskem & BM\&FBOVESPA \\
\hline$\beta 0$ (Intercepto) Estimado & 0.01080451 & -0.02595633 & 0.00534755 & -0.00346018 & -0.00631135 & 0.00173798 & 0.0144783 & 0.00612943 \\
\hline Erro Padrão & 0.01005937 & 0.01964691 & 0.01016765 & 0.00823342 & 0.00864843 & 0.01065466 & 0.0164255 & 0.01648470 \\
\hline Estatística t & 1.07407 & 1.32114 & 0.52594 & -0.42026 & -0.72977 & 0.16312 & 0.88145 & 0.37183 \\
\hline$P$-Valor & 0.2865311 & 0.190819 & 0.60062 & 0.67560 & 0.46800 & 0.87090 & 0.3811335 & 0.711179 \\
\hline Dummy Dit & 0.00643738 & 0.00135162 & 0.00540732 & 0.01592239 & 0.00227354 & 0.01807958 & -0.0188317 & -0.01487523 \\
\hline Erro Padrão & 0.01444391 & 0.02822911 & 0.01467446 & 0.01189456 & 0.01364940 & 0.01526664 & 0.0240289 & 0.02352011 \\
\hline Estatística t & 0.44568 & 0.04788 & 0.36848 & 1.33863 & 0.16657 & 1.18425 & -0.78371 & -0.63245 \\
\hline P-Valor & 0.6572228 & 0.961950 & 0.71364 & 0.18509 & 0.86820 & 0.24038 & 0.4358933 & 0.529216 \\
\hline$R m_{t}$ & 0.38481633 & 1.20593195 & 1.30905120 & 0.87064479 & 1.27566091 & 0.78917233 & 0.6548243 & 0.66534671 \\
\hline Erro Padrão & 0.12110179 & 0.23574074 & 0.12370454 & 0.09666108 & 0.10733032 & 0.12711175 & 0.2162791 & 0.15979439 \\
\hline Estatística t & 3.17763 & 5.11550 & 10.58208 & 9.00719 & 11.88537 & 6.20849 & 3.02768 & 4.16377 \\
\hline$P$-Valor & 0.0022223 ** & $2.6836 \mathrm{e}-06^{* \star *}$ & $4.4409 \mathrm{e}-16^{* \star *}$ & $2.8955 \mathrm{e}-13^{* \star *}$ & $<2 \mathrm{e}-16^{* \star *}$ & $3.4977 \mathrm{e}-08^{* \star \star}$ & 0.0034638 ** & $9.0185 \mathrm{e}-05^{\star \star \star}$ \\
\hline$\beta_{3} R m_{t} D_{i t}^{p o s}$ & -0.29259877 & -0.89381409 & -0.13303613 & -0.27206723 & -0.31198626 & -0.23952318 & 0.3698513 & -0.72121957 \\
\hline Erro Padrão & 0.23292073 & 0.45221464 & 0.23856417 & 0.18423606 & 0.22658313 & 0.24297958 & 0.4169643 & 0.32253705 \\
\hline Estatística t & -1.25622 & -1.97653 & -0.55765 & -1.47673 & -1.37692 & -0.98577 & 0.88701 & -2.23608 \\
\hline$P$-Valor & 0.2132743 & 0.052094 . & 0.57889 & 0.14430 & 0.17299 & 0.32769 & 0.3781552 & 0.028631 * \\
\hline $\begin{array}{l}\text { Soma dos quadrados da } \\
\text { regressao (SSR) }\end{array}$ & 0.270936 & 1.024333 & 0.274225 & 0.183831 & 0.287489 & 0.290154 & 0.850459 & 0.698247 \\
\hline Erro quadrático médio (MSE) & 0.003927 & 0.014845 & 0.003974 & 0.002664 & 0.004167 & 0.004205 & 0.012325 & 0.010268 \\
\hline $\begin{array}{l}\text { Raiz do erro quadrado médio } \\
\text { (Root MSE) }\end{array}$ & 0.062663 & 0.121842 & 0.063042 & 0.051616 & 0.064548 & 0.064847 & 0.11102 & 0.101333 \\
\hline R Quadrado & 0.144748 & 0.258627 & 0.674414 & 0.563306 & 0.581163 & 0.358324 & 0.166476 & 0.098774 \\
\hline R Quadrado Ajustado & 0.107563 & 0.226393 & 0.660259 & 0.544319 & 0.562953 & 0.330425 & 0.130236 & 0.059014 \\
\hline
\end{tabular}

Fonte: Dados da pesquisa (2016).

Tabela 3- Continuação...

\begin{tabular}{|c|c|c|c|c|c|c|c|c|}
\hline Variável Empresa & CCR & Cielo & CEMIG & $\cos A N$ & Fibria & Itausa & $\begin{array}{c}\text { Itaú } \\
\text { Unibanco }\end{array}$ & $J B S$ \\
\hline Bo (Intercepto) Estimado & 0.01253449 & -0.01013571 & -0.000953143 & 0.01078426 & -0.00763059 & 0.00596777 & 0.00230031 & -0.00443353 \\
\hline Erro Padrão & 0.00988213 & 0.00906826 & 0.012989877 & 0.01790926 & 0.01402555 & 0.00889343 & 0.00982913 & 0.01747344 \\
\hline Estatística t & 1.26840 & -1.11771 & -0.07338 & 0.60216 & -0.54405 & 0.67103 & 0.23403 & -0.25373 \\
\hline$P$-Valor & 0.208918 & 0.267566 & 0.9417194 & 0.5490408 & 0.588161 & 0.50444 & 0.815655 & 0.80046 \\
\hline Dummy Dit & -0.00495494 & 0.01537451 & 0.005938577 & -0.00444956 & 0.01146056 & -0.00439584 & 0.00142930 & 0.02779091 \\
\hline Erro Padrão & 0.01412114 & 0.01299515 & 0.018616346 & 0.02520767 & 0.02007826 & 0.01286038 & 0.01418695 & 0.02499352 \\
\hline Estatística t & -0.35089 & 1.18310 & 0.31900 & -0.17652 & 0.57079 & -0.34181 & 0.10075 & 1.11192 \\
\hline P-Valor & 0.726741 & 0.240831 & 0.7506917 & 0.8604057 & 0.569993 & 0.73353 & 0.920043 & 0.27003 \\
\hline$R m_{t}$ & 0.65335559 & -0.00743350 & 0.453917059 & 0.69485228 & 0.29382260 & 0.94177034 & 1.02985864 & 0.96846659 \\
\hline Erro Padrão & 0.11924218 & 0.10815337 & 0.153315313 & 0.20959392 & 0.16850990 & 0.10420633 & 0.11546644 & 0.21022472 \\
\hline Estatística t & 5.47923 & -0.06873 & 2.96068 & 3.31523 & 1.74365 & 9.03755 & 8.91912 & 4.60682 \\
\hline P-Valor & $6.5245 \mathrm{e}-07^{* * *}$ & 0.945402 & $0.0042054 * *$ & $0.0014621^{* *}$ & 0.085674 . & $2.5491 \mathrm{e}-13^{* * *}$ & $4.1878 \mathrm{e}-13^{* * *}$ & $1.8157 \mathrm{e}-05^{* * *}$ \\
\hline$\beta_{3} R m_{t} D_{i t}^{p o s}$ & -0.53384753 & -0.36863198 & -0.244237091 & -0.23793198 & 0.45363359 & -0.38263094 & -0.40919861 & 0.63253483 \\
\hline Erro Padrão & 0.22925703 & 0.20732587 & 0.293587138 & 0.39744140 & 0.32298756 & 0.19855596 & 0.21981750 & 0.39672831 \\
\hline Estatística t & -2.32860 & -1.77803 & -0.83191 & -0.59866 & 1.40449 & -1.92707 & -1.86154 & 1.59438 \\
\hline$P$-Valor & 0.022817 * & 0.079805 . & 0.4083315 & 0.5513604 & 0.164658 & 0.05809 & 0.066928 . & 0.11542 \\
\hline $\begin{array}{l}\text { Soma dos quadrados da regressao } \\
\text { (SSR) }\end{array}$ & 0.246541 & 0.20781 & 0.448702 & 0.957586 & 0.494071 & 0.223664 & 0.267549 & 0.830874 \\
\hline Erro quadrático médio (MSE) & 0.003573 & 0.003012 & 0.006503 & 0.013878 & 0.00716 & 0.003242 & 0.003878 & 0.012042 \\
\hline $\begin{array}{l}\text { Raiz do erro quadrado médio } \\
\text { (Root MSE) }\end{array}$ & 0.059775 & 0.054879 & 0.080641 & 0.117805 & 0.084619 & 0.056934 & 0.06227 & 0.109734 \\
\hline R Quadrado & 0.322108 & 0.103039 & 0.0665 & 0.205189 & 0.155818 & 0.567886 & 0.558413 & 0.367289 \\
\hline R Quadrado Ajustado & 0.292635 & 0.064041 & 0.025913 & 0.170632 & 0.119115 & 0.549098 & 0.539214 & 0.33978 \\
\hline
\end{tabular}

Fonte: Dados da pesquisa (2016).

Tabela 3 - Continuação... 
RETORNO DAS AÇÕES E SENSIBILIDADE AO RISCO DE MERCADO DAS EMPRESAS PARTICIPANTES DO ÍNDICE CARBONO EFICIENTE (ICO2) DA B3 S.A.: UM ESTUDO COMPARATIVO

\begin{tabular}{|c|c|c|c|c|c|c|c|c|c|c|c|c|}
\hline rom & $\begin{array}{c}\text { Lojas } \\
\text { Americanas }\end{array}$ & Lojas Renner & MMX & $\begin{array}{c}\text { MRV } \\
\text { Engenharia }\end{array}$ & Natura & $O G X$ & PDG & $\begin{array}{c}\text { Banco } \\
\text { Santander }\end{array}$ & $\begin{array}{c}\text { Tim } \\
\text { Participaçōes }\end{array}$ & Vale (Vale 3) & Vale (Vale 5) & $\begin{array}{l}\text { Telefônica } \\
\text { Brasil//Vivo }\end{array}$ \\
\hline BO (Intercepto) Estimado & & 75738 & 2474183 & & 244557 & 288628 & 75477 & 0371875 & & 0638237 & 00448360 & 005005 \\
\hline Erro Padrão & 0.01232676 & 0131535 & 0.02646857 & 0.0185174 & 0.0107227 & 0.0294503 & 0181592 & 01095055 & 0.0182422 & .00728712 & 0.00681245 & 0.00747016 \\
\hline Estatísticat & 0.15190 & 1.33606 & 0.17915 & 0.82646 & 2.28074 & 0.98005 & 0.96632 & -0.33959 & -0.86087 & -0.87584 & -0.65815 & -0.67003 \\
\hline P-Valor & 0.87971 & 0.185921 & 0.858345 & 0.41139 & $0.025656^{*}$ & 0.33053459 & 0.337258 & 0.73521 & 0.392289 & 0.38415 & 0.51263 & 0.50508 \\
\hline Dummy Dit & 0.00472761 & -0.0137487 & -0.06625718 & -0.0196931 & -0.0273408 & -0.1483507 & -0.0491257 & -0.01372853 & 0.0343788 & 0.00515081 & 0.00416830 & 0.01007585 \\
\hline Erro Padrão & 0.01759761 & 0.0187672 & 0.03809711 & 0.0261697 & 0.0153546 & 0.0417654 & 0.0259860 & .01572357 & 0.0262363 & & 0.01098223 & 0.01070817 \\
\hline Estatísticat & 0.26865 & -0.73259 & -1.73917 & -0.75252 & -1.78063 & -3.55200 & -1.89047 & -0.87312 & 1.31035 & 0.44008 & 0.37955 & 0.94095 \\
\hline P-Valor & 0.78900 & 0.466289 & 0.086465. & 0.45430 & 0.079375. & $0.00069975^{* * *}$ & 0.062896 . & 0.38567 & 0.194422 & 0.66125 & 0.70545 & 0.35001 \\
\hline$R m_{t}$ & 1.09705222 & 1.3889787 & 2.43128003 & 1.7491680 & 0.1710393 & 0.9899364 & 1.3670724 & -0.09280311 & 0.5374024 & 1.14120011 & 1.09746087 & -0.09097027 \\
\hline Erro Padrão & 0.14666202 & 0.1594828 & 0.31605481 & 0.2211519 & 0.1261108 & 0.3475827 & 0.2185425 & 0.11144298 & 0.2200884 & 0.09074551 & 0.08473490 & 0.08936407 \\
\hline Estatisticat & 7.48014 & 8.70927 & 7.69259 & 7.90935 & 1.35626 & 2.84806 & 6.25541 & -0.83274 & 2.44176 & 12.57583 & 12.95170 & -1.01797 \\
\hline P-Valor & $1.78140-10^{* * *}$ & $1.0103 e-12^{*+x}$ & $7.29240-11^{* * *}$ & $2.9283 \mathrm{e}-11^{* * * x}$ & 0.179437 & $0.00581300^{* *}$ & 2.8879e-08 & 0.40791 & 0.017184 * & $<2 e-16^{* * *}$ & $<20-16^{* * *}$ & 0.31225 \\
\hline$\beta_{3} R m_{t} D_{i t}^{\text {pos }}$ & -0.44852905 & -0.6265020 & -0.66771175 & -0.0655260 & 0.1886525 & 0.2630774 & 0.2230884 & -0.00951041 & 0.0285396 & -0.24416515 & -0.19845481 & 0.24399959 \\
\hline Erro Padrão & 0.28143751 & 0.3069430 & 0.58850603 & 0.4208255 & 0.2402379 & 0.5617084 & 0.4134673 & 0.20951847 & 0.4247765 & 0.19451487 & 0.18224992 & 0.17041330 \\
\hline Estatísticat & -1.59371 & -2.04110 & -1.13459 & -0.15571 & 0.78527 & 0.46835 & 0.53956 & -0.04539 & 0.06719 & -1.25525 & -1.08892 & 1.43181 \\
\hline P-Valor & 0.11557 & 0.045068 * & 0.260474 & 0.87672 & 0.434981 & 0.64103060 & 0.591241 & 0.96393 & 0.946627 & 0.21362 & 0.27998 & 0.15671 \\
\hline $\begin{array}{l}\text { Soma dos quadrados da regressao } \\
\text { (SSR) }\end{array}$ & 0.42403 & 0.48615 & 1.86191 & 0.870505 & 0.310379 & 2.211471 & 0.842902 & 0.313819 & 0.853837 & 0.206095 & 0.184476 & 0.145573 \\
\hline Erro quadrático médio (MSE) & 0.006145 & 0.007046 & 0.026984 & 0.012616 & 0.004498 & 0.032522 & 0.012216 & 0.004615 & 0.012374 & 0.002987 & 0.002674 & 0.00211 \\
\hline $\begin{array}{l}\text { Raiz do erro quadrado médio } \\
\text { (Root MSE) }\end{array}$ & 0.078392 & 0.083938 & 0.164269 & 0.112321 & 0.067069 & 0.180338 & 0.110526 & 0.067934 & 0.111241 & 0.054652 & 0.051706 & 0.045932 \\
\hline R Quadrado & 0.509232 & 0.55491 & 0.470585 & 0.579744 & 0.166177 & 0.297599 & 0.488402 & 0.002902 & 0.086469 & 0.598901 & 0.600478 & 0.026918 \\
\hline Quadrado Ajustado & 0.487895 & 0.535558 & 0.447567 & 0.561472 & 0.129924 & 0.266611 & 0.466159 & -0.041087 & 0.04675 & 0.581462 & 0.583108 & 0.015389 \\
\hline
\end{tabular}

Legenda - Níveis de significância:

‘***' 0.001

‘**, 0.01

'*' 0.05

$\because 0.1$

', 1

Fonte: Dados da pesquisa (2016).

A partir dos resultados das tabelas acima, conforme a variável $\beta_{1}$, a hipótese nula $\left(\mathrm{H}_{30}\right)$ não foi rejeitada, pois verificou-se que no geral, os retornos individuais, das ações das empresas da amostra do estudo "b", não apresentaram alterações estatisticamente significativas no período pós-ingresso no ICO2 em relação ao período anterior ao ingresso no índice. Esse resultado, que rejeitou a hipótese alternativa $\left(\mathrm{H}_{31}\right)$, converge com os resultados encontrados anteriormente, por meio da regressão em Painel com os modelos MMQ/OLS (Tabela 8).

Contudo, algumas exceções foram observadas, para as quais a hipótese $\mathrm{H}_{30}$, foi rejeitada, aceitando-se, portanto, a hipótese alternativa $\left(\mathrm{H}_{31}\right)$. Os retornos $\left(\beta_{1}-\right.$ Dummy Dit $)$ das ações das empresas Natura, a um nível de significância de $10 \%$, com o p-valor de 0.079375 , assim como os retornos das ações da empresa OGX a um nível de significância de 5\%, com o p-valor de 0.00069975 e os retornos das ações das empresas MMX e PDG, a um nível de significância de $10 \%$, com o p-valor de 0.086465 e 0.062896 , respectivamente, apresentaram alterações negativas, após ingresso no ICO2. Para essas empresas, os resultados corroboraram com os achados das pesquisas de Buosi (2014).

Embora sem significância estatística, 8 dos 28 papéis das 27 empresas do estudo "b" (Braskem, B3, CCR, COSAN, Itausa, Lojas Renner, MRV e Santander) apresentaram no período, pós ingresso na iniciativa, retornos negativos. 
Em relação à variável $\beta_{3}$, verificou-se que a hipótese nula $\left(\mathrm{H}_{40}\right)$ não foi rejeitada, pois, em sua maioria, as ações das empresas no período, pós ingresso no ICO2, não sofreram alterações na sensibilidade ao risco do mercado, rejeitando-se a hipótese alternativa $\left(\mathrm{H}_{41}\right)$.

Somente para alguns casos, aceitou-se a hipótese alternativa $\left(\mathrm{H}_{41}\right)$. A hipótese $\mathrm{H}_{41}$ não foi rejeitada, considerando um nível de significância de 5\%, para os papéis das empresas B3 (p-valor de 0.028631), CCR (p-valor de 0.022817) e Lojas Renner (p-valor de 0.045068) e a um nível de significância de 10\% para os papéis das empresas América Latina Logística (pvalor de 0.052094), Cielo (p-valor de 0.079805), Itausa (p-valor de 0.05809) e Itaú Unibanco (p-valor de 0.066928). Logo, nesses casos verificou-se alterações na sensibilidade ao risco de mercado, no período de pós-admissão no ICO2. Os achados para estas empresas corroboraram com os resultados das pesquisas de Teixeira, Nossa e Funchal (2011), Milani et al., (2012) e Andrade et al. (2013), indicando que nessas empresas a exposição ao risco de mercado foi menor. Para estes casos, a hipótese nula $\mathrm{H}_{40}$ foi rejeitada.

Observou-se, também, embora sem significância estatística, que 13 dos 28 papéis das empresas do estudo "b" (Ambev, Banco do Brasil, Bradesco, Bradespar, BRF Foods, Cemig, Cosan, Lojas Americanas, MMX, MRV, Santander, Vale (2 papéis) apresentaram alterações negativas na sensibilidade ao risco de mercado, no período de pós-admissão no ICO2.

É importante destacar que, conforme discutido anteriormente, a participação relativa das ações das empresas na carteira teórica do ICO2 (performance) é ponderada pela eficiência no combate às emissões de GEE e o número total de ações circulando (free float) (B3, 2018a). Logo, quanto maior for a ecoeficiência e o volume total de ações em circulação da empresa, melhor será a sua participação relativa na carteira. Embora a presença de grandes empresas na amostra, a exemplo das destacadas acima, pode induzir um viés de análise já que têm maior participação na composição dos índices, acredita-se que essa maior participação não comprometa a análise, pois, individualmente, cada empresa não representava mais do que $4 \%$ na composição da carteira do IBrX-50 utilizada como base para a investigação, com exceção da Vale (com 2 papéis) com participação de 10,2\% e o Bradesco com participação de 6,6\%. Em relação as demais empresas acima destacadas, as participações na carteira do IBrX-50 eram de 4\% (Ambev), 3\% (Banco do Brasil), 1\% (Bradespar e Cemig, cada), 2\% (BRF Foods e Santander, cada), 0,3\% (Cosan e MMX, cada), 0,4\% (Lojas Americanas) e 0,5\% (MRV).

É importante, contudo, destacar que além da performance dos papéis das empresas na carteira teórica de índices de sustentabilidade, a exemplo do ICO2/B3, ser um dos fatores que pode contribuir para a redução da sensibilidade das ações ao risco de mercado, os investidores devem considerar, também, para auxiliar a decisão de investimentos, a liderança setorial das empresas, as boas práticas de governança corporativa (GOMES et al., 2017), os fundamentos de gestão (AL-TUWAIJRI, CHRISTENSEN; HUGHES, 2004; LEMME, 2010) além dos níveis de alavancagem e natureza cíclica das receitas (MANDELKER; RHEE, 1984; BRIGHAM; GAPENSKI; EHRHARDT, 2001; DANTAS et al., 2006; ASSAF NETO, 2010; GITMAN, 2010) pois tais fatores podem influenciar na sensibilidade das ações das corporações ao risco de mercado.

\section{CONCLUSÃO E RECOMENDAÇÕES FINAIS}

A presente pesquisa teve por objetivo examinar qual a relação entre a participação das empresas no ICO2/B3 (proxy) e o retorno e sensibilidade de suas ações ao risco de mercado visando subsidiar a tomada de decisão por parte das empresas e investidores. Para tal, realizaram-se dois estudos denominados "a" e "b". No estudo "a", fez-se uma comparação de grupos de empresas que participam e que não participam do ICO2. Já no estudo "b" realizouse uma avaliação no grupo de empresas do ICO2.

Em relação aos achados do estudo "a", encontrou-se que o grupo de 27 empresas admitidas no ICO2 não apresentaram retornos das ações superiores quando comparado com o 
grupo de 8 empresas do IBrX-50, que não estavam admitidas no ICO2. Ainda em relação ao estudo "a", verificou-se que o grupo de 27 empresas admitidas no ICO2 apresentaram baixa sensibilidade ao risco de mercado, quando comparado com o grupo de 8 empresas do IBrX-50, que não ingressou no ICO2.

Assim, pode-se inferir que, embora não tenham ocorrido alterações nos retornos das ações das empresas do estudo "a", a sensibilidade ao risco de mercado é menor para o grupo de 27 empresas que ingressaram no ICO2 se comparado com o grupo de 8 empresas que não ingressaram nesse índice, com o modelo utilizado nessa pesquisa.

Em relação ao estudo "b", verificou-se que os retornos das ações das empresas que ingressaram no ICO2, após admissão na carteira teórica do índice, não apresentaram alterações, ante o período que antecedeu o seu ingresso nessa iniciativa. Verificou-se, também, que a sensibilidade ao risco de mercado das ações das empresas, após admissão na carteira teórica do ICO2, não foi alterada, se comparado ao período de pré-admissão.

Dessa forma, a presente pesquisa contribuiu tanto para aumentar o conhecimento teórico sobre a problemática estudada quanto para os agentes do mercado, ao evidenciar que, apesar do ingresso de empresas no ICO2 não influenciar nos retornos de suas ações, a participação no ICO2 reduz a sensibilidade de seus papéis ao risco de mercado e, consequentemente, tais papéis podem oferecer menor risco sistemático ao investidor quando comparado com os papéis de empresas que não participam desse índice. Nesse sentido, essa pesquisa gerou conhecimento que pode apoiar o processo de tomada de decisões tanto por parte dos investidores quanto por parte das empresas, ao verificar que o ICO2, iniciativa de sustentabilidade criada pelo mercado, focada nas questões climáticas, afigura-se um fator que pode contribuir para a redução da sensibilidade das ações das empresas participantes ao risco de mercado.

Isto posto, ao verificar que as empresas, participantes do ICO2, apresentaram menor sensibilidade ao risco de mercado quando comparado com empresas que não participavam dessa iniciativa, a presente pesquisa traz elementos que podem auxiliar os investidores melhorarem as suas decisões de investimentos quando o objetivo for a busca de papéis que ofereceram menor sensibilidade ao risco de mercado para alocação de investimentos. Assim, os resultados sugerem que empresas menos sensíveis ao risco de mercado são mais propensas à adesão ao ICO2 e essa adesão não necessariamente implica maiores retornos financeiros. No entanto, cabe destacar que a decisão de investimentos de recursos em empresas, particularmente, em ações de organizações que figuram em carteira teóricas de índices de sustentabilidade, a exemplo do ICO2, deve ser ponderada não só pela participação da empresa nessas iniciativas, mas levando em consideração, também, às práticas de governança corporativa, a performance econômico-financeira da companhia no setor e no mercado e os fundamentos econômicos de gestão de forma a maximizar os seus resultados esperados. Destaca-se, contudo, que a análise focada apenas nas empresas pertencentes ao ICO2/B3 constitui-se em uma limitação da presente pesquisa.

Por fim, recomenda-se a realização de pesquisas futuras, considerando outras variáveis dependentes além dos retornos das ações (retorno sobre os investimentos, retorno sobre os ativos e o Q de Tobin) e independentes além do Ibovespa (Índice de Sustentabilidade Empresarial (ISE), Índice Carbono Eficiente (ICO2) e o Índice de ações com governança corporativa diferenciada - IGCX, ambos da B3 S.A.). Nesse sentido, pode-se realizar, também, testes comparativos de médias, com amostras diferentes, por meio do teste $t$, como também a realização de testes não paramétricos nos dados. Ademais, considerando-se ainda as limitações do $C A P M$, cujo alfa da regressão deverá ser igual a zero e levando-se em consideração a premissa de mercado eficiente, sugere-se a utilização de outros modelos, a exemplo do modelo estatístico, o modelo Arbitrage Princing Theory - APT ou outro para verificar a existência ou não de retornos diferenciais em relação ao ajuste a risco do mercado, já que, através do $C A P M$, não é uma tarefa simples. 


\section{REFERÊNCIAS}

ALBARELLO, L.; DIGNEFFE, F.; HIERNAUX, J.; MAROY, C.; RUQUOY, D.; SAINTGEORGES, P. Práticas e Métodos de Investigação em Ciências Sociais. 3a. Ed. Lisboa: Gradativa Publicações, 2011.

AL-TUWAIJRI, S. A.; CHRISTENSEN, T. E.; HUGHES II, K. E. The relations among environmental disclosure, environmental performance and economic performance: a simultaneous equations approach. In: Accounting, Organizations and Society. v. 29, p. 447471. 2004.

AMARAL, P. C. Responsabilidade Social Corporativa e Economia de Baixo Carbono: Relação entre desempenho ambiental e desempenho financeiro no setor de minero metalúrgico brasileiro. 2012. 141f. (Dissertação de Mestrado). Programa de Pós-Graduação em Planejamento Energético, COPPE, da Universidade Federal do Rio de Janeiro. 2012.

ANDRADE, L. P.; BRESSAN, A. A.; IQUIAPAZA, R. A.; MOREIRA, B. C. M. Determinantes de adesão ao Índice de Sustentabilidade Empresarial da BM\&FBOVESPA e sua relação com o valor da empresa. In: Revista Brasileira de Finanças, v.11, n. 2. p. 181213. 2013.

ARAÚJO, E. A. T.; OLIVEIRA, V. C.; SILVA, W. A. C. CAPM em estudos brasileiros: uma análise da pesquisa. In: Revista de Contabilidade e Organizações. v. 16. n. 15. p. 95-122. 2012.

ASSAF NETO, A. Finanças corporativas e valor. 5a . Ed. São Paulo: Atlas, 2010.

BARBOSA, J. S.; ALTOÉ, S. M. L.; SILVA, W. V.; ALMEIDA, L. B. Índice Carbono Eficiente (ICO2) e retorno das Ações: um estudo de eventos em empresas não financeiras de capital aberto. In: Revista de Contabilidade e Organizações. n. 19. pp. 59-69. 2013.

BASSEN, A.; MEYER, K.; SCHLANGE, J. The Influence of Corporate Responsibility on the Cost of Capital. Universitat Hamburg. p. 1-47. 2006.

BOLSA DE VALORES, MERCADORIAS E FUTUROS DE SÃO PAULO (BM\&FBOVESPA). (2015a). Índices. Disponível em: < http://www.bmfbovespa.com.br/indices/BuscarIndices.aspx?idioma=pt-br $>$. Acesso em: $12 \mathrm{de}$ outubro de 2015.

Metodologia do Índice Carbono Eficiente (ICO2). 2015b. Disponível em: $<$ http://www.bmfbovespa.com.br/Indices/download/ICO2-Metodologia-pt-br.pdf $>$. Acesso em: 29 de dezembro de 2015.

Índice Carbono Eficiente - ICO2. 2014a. Disponível

em: $<$ http://www.bmfbovespa.com.br/indices/ResumoIndice.aspx? Indice=IBrX50\&idioma=pt -br>. Acesso em: 09 de outubro de 2014.

. Índice Brasil 50 - IbrX-50. 2014b. Disponível

$\mathrm{em}:<$ http://www.bmfbovespa.com.br/indices/ResumoIndice.aspx? Indice $=I B r X 50 \&$ idioma $=\mathrm{pt}$ -br>. Acesso em: 09 outubros 2014. 
RETORNO DAS AÇÕES E SENSIBILIDADE AO RISCO DE MERCADO DAS EMPRESAS PARTICIPANTES DO ÍNDICE CARBONO EFICIENTE (ICO2) DA B3 S.A.: UM ESTUDO COMPARATIVO

Diretrizes para a contabilização, cálculo e relato de emissões de gases de efeito estufa (GEE) para fins do ICO2. 2013. Disponível em: $<$ http://www.bmfbovespa.com.br/Indices/download/Diretrizes-ICO2.pdf $>$. Acesso em: 09 de outubro 2014.

BOYD, E.; BOYKOFF, M.; NEWELL, P. The "New" Carbon Economy: What's New? Editorial Board of Antipode, v..43, n. 3, p. 601-611, 2011.

BRASIL, BOLSA, BALCÃO (B3). Índice Carbono Eficiente (ICO2). 2018a. Disponível em: $<$ http://www.b3.com.br/pt_br/market-data-e-indices/indices/indices-desustentabilidade/indice-carbono-eficiente-ico2.htm>. Acesso em: 01 de novembro de 2018.

Índice de Sustentabilidade Empresarial (ISE). 2018b. Disponível em:

$<$ http://www.b3.com.br/pt_br/market-data-e-indices/indices/indices-desustentabilidade/indice-de-sustentabilidade-empresarial-ise.htm>. Acesso em: $01 \mathrm{de}$ novembro de 2018.

BOLSA DE VALORES, MERCADORIAS E FUTUROS DE SÃO PAULO (BM\&FBOVESPA); MACEDO, F.; BARBOSA, H.; CALLEGARI, I.; MONZONI, M.; SIMONETTI, R. O Valor do ISE: Principais Estudos e a perspectiva dos investidores. 2012. Disponível em:

$<$ http://www.bmfbovespa.com.br/lumis/portal/file/fileDownload.jsp?fileId=8AA8D09752D53 1A301531486394A7767>. Acesso em: 22 de novembro de 2016.

BRIGHAM, E.F.; GAPENSKI, L. C.; EHRHARDT, M. C. Administração Financeira: Teoria e Prática. São Paulo: Atlas, 2001.

BROWN, S., WARNER, J. Measuring security price performance. In: Journal of Financial Economics, v. 8, n.3, p. 205-258. 1980.

BUOSI, M. E. S. Estudo de Correlação e Causalidade entre o Desempenho Financeiro e de Eficiência no Combate às Emissões de Gases de Efeito Estufa das Empresas do Mercado de Capitais Brasileiro. 2014. 101f. (Dissertação de Mestrado). Programa de PósGraduação em Economia e Administração. Universidade de São Paulo. Faculdade de Economia e Administração.

CAMARGOS, M. A., BARBOSA, F. V. Estudos de Eventos: Teoria e Operacionalização. In: Cadernos de Pesquisa em Administração. São Paulo, v. 10, nº 3, p. 01-20, jul/set. 2003.

CARBON DISCLOSURE PROJECT (CDP). Conexão entre mudanças climáticas e modelos de negócios: uma agenda em evolução: CDP mudanças climáticas Brasil 100, 2014. 2014. Disponível em: $<$ https://www.cdp.net/CDPResults/CDP-brazil-climate-change-report2014-portuguese.pdf >. Acesso em: 29 out. 2015.

CAVAlCANTE, L. R. M. T.; BRUNI, A. L.; COSTA, F. J. M. Sustentabilidade Empresarial e Valor das Ações: Uma análise da bolsa de valores de São Paulo. In.: Revista de Gestão Social e Ambiental (RGSA). v. 3, n. 1, p. 70-86, jan./abr. 2009. 
André L. R. de Souza - Antônio F. A. da Silva Junior - José C. S. Andrade - Maria Eduarda S. T. Fernandes

CORREIA, A. M. R.; MESQUITA, A. Mestrados \& Doutoramentos: Estratégias para a elaboração de trabalhos científicos: o desafio da excelência. $2^{\mathrm{a}}$. ed. Porto: Vida Econômica - Editorial, 2014.

CRUZ, T. S. Evidenciação de informações de enfrentamento às mudanças climáticas e desempenho econômico-financeiro: um estudo com as empresas listadas no ISE da BM\&FBOVESPA. 2015. 75f. (Dissertação de Mestrado). Programa de Pós-Graduação Strictu Sensu em Contabilidade. Faculdade de Ciências Contábeis. Universidade Federal da Bahia.

CRUZ, T. S.; GOMES, S. M. S.; OLIVEIRA, N. C.; OLIVEIRA, N. S. Estratégias de Enfrentamento às Mudanças Climáticas: Um estudo com as empresas listadas no Índice de Sustentabilidade Empresarial da B3. In: Revista de Administração da UFSM. V. 10, Edição Especial. P. 149-166. 2017.

DANTAS, J. A; MEDEIROS, O. R.; LUSTOSA, P. R. Reação do mercado à alavancagem operacional: um estudo empírico no Brasil. In: Revista de Contabilidade \& Finanças, v. 17, n. 41, p. 72-86. 2006.

DIAS-FILHO, J. M. A Pesquisa Qualitativa sob a Perspectiva da Teoria da Legitimidade: uma alternativa para explicar e predizer políticas de evidenciação contábil. Revista Interface, Botucatu, v. 9, n. 1, p. 72-86, 2012.

FARIAS, L. G. Q. de. Estratégias de Legitimidade de Suchman Evidenciadas pelas Empresas Brasileiras Destinatárias do Pedido do Carbon Disclosure Project (CDP). 2013. 207 f. Tese (Doutorado) - Escola de Administração, Universidade Federal da Bahia, Salvador.

FERREIRA, L.; SARMENTO, M. Da Investigação Quantitativa em Contabilidade: Investigação por Inquérito. In: MAJOR, M. J.; VIEIRA, R. (Orgs.). Contabilidade e Controlo de Gestão: Teoria, Metodologia e Prática. Lisboa: Escolar Editora, 2009.

FREEDMAN, M.; Jaggi, B. An investigation of the long-run relationship between pollution performance and economic performance: The case of pulp-and-paper firms. In: Critical Perspectives on Accounting, v. 3, n. 4, p. 315-336. 1992.

FREEMAN, R. E.; HARRISON, J. S.; WICKS, A. C.; PARMAR, B. L. COLLE, S. Stakeholder theory: The state of the art. New York: Cambridge University Press. p. 1-343. 2010.

FEBRA, L. C.M. Liquidez e Rendibilidade das Acções de Empresas Admitidas em Bolsa Estrangeiras. 2010. Tese (Doutorado) - Instituto Superior de Economia e Gestão, Universidade Técnica de Lisboa. Lisboa, 2010.

GITMAN, L. J. Princípios de Administração Financeira. 12a. Ed. São Paulo: Pearson Prentice Hall. 2010.

GOMES, S. M. S.; KOUI, D. K.; BRUNI, A. L.; OLIVEIRA, N. C. Relação entre o Disclosure de Riscos Climáticos e o Retorno Anormal das Empresas Brasileiras. In: Revista Universo Contábil. V. 13, N. 2, p. 149-165. Abr./jun., 2017. 
RETORNO DAS AÇÕES E SENSIBILIDADE AO RISCO DE MERCADO DAS EMPRESAS PARTICIPANTES DO ÍNDICE CARBONO EFICIENTE (ICO2) DA B3 S.A.: UM ESTUDO COMPARATIVO

HILL, R. C.; G, W.E.; JUDGE, G.G. Econometria. 2a. ed. São Paulo: Saraiva. 2006.

HOLLAND, M.; XAVIER, C. L. Dinâmica e competitividade setorial das exportações brasileiras: uma análise de painel para o período recente. In: Economia e Sociedade. v. 14. n. 1. p. 85-108. jan./jun. 2005.

INTERGOVERNMENTAL PANEL ON CLIMATE CHANGE (IPCC). The physical science basis. Working Group I Contribution to the IPCC Fifth Assessment Report Climate Change. 2013. Disponível em: http://www.climatechange2013.org/. Acesso em: 06 nov. 2018.

KOLK, A.; PINKSE, J. Towards Strategic Stakeholder Management? Integrating Perspectives on Corporate Responses to Climate Change. In: Corporate Governance: The International Journal of Business in Society, v. 7, n. 4, p. 370-378. 2007.

KOLK, A; LEVY, D; PINKSE, J. Corporate Responses in an Emerging Climate Regime: The Institutionalization and Commensuration of Carbon Disclosure. European Accounting Review, v. 17, n. 4, 2008, pp. 719-745.

LABATT, S.; WHITE, R. R. Carbon Finance: the financial implications of Climate Change. John Wiley \& Sons, Inc., Hoboken, New Jersey. 2007.

LOURENÇO, I. C.; BRANCO, M. C.; CURTO, J. D.; EUGÉNIO, T. P. How Does the Market Value Corporate Sustainability Performance? In.: Springer Science Business Media. v. 108, n. 4, p. 417-428. 2011.

MACKINLAY, A. Event Studies in Economics and Finance. In: Journal of Economic Literature. Vol. XXXV (march), pp. 13-39. 1997.

MARCONI, M. A.; LAKATOS, E. M. Metodologia Científica. 6. ed. São Paulo: Atlas, 2011.

MANDELKER, G. N.; RHEE, S. G. The impact of the degrees of operating and financial leverage on systematic risk of common stock. In: Journal of Financial and Quantitative Analysis, v. 19, n. 01, p. 45-57. 1984.

MILANI, B.; RIGHI, B. R.; CERETTA, P. S.; DIAS, V. V. Práticas de Sustentabilidade, Governança Corporativa e Responsabilidade Social afetam o Risco e Retorno dos Investimentos? In.: Revista de Administração da Universidade de Santa Maria. v.5, Edição Especial, p. 667-682, dez. 2012.

MISANI, N.; POGUTZ, S. Unraveling the effects of environmental outcomes and processes on financial performance: A non-linear approach. In: Ecological Economics, v. 109, p. 150160. 2015.

NEVES, J. C. das. Avaliação de Empresas e Negócios. Lisboa: McGraw-Hill de Portugal. 2002. 
André L. R. de Souza - Antônio F. A. da Silva Junior - José C. S. Andrade - Maria Eduarda S. T. Fernandes

NEWELL, P.; BOYKOFF, M.; BOYD, E. The New Carbon Economy: Constitution, governance and contestation. Wiley-BlackWell, v. 43, n. 3, 2012.

OLIVEIRA, A. F.; MACHADO, D. G.; BEUREN, I. M. Evidenciação ambiental de empresas de setores potencialmente poluidores listados no Índice de Sustentabilidade Empresarial (ISE). In: Revista de Gestão Social e Ambiental (RGSA). São Paulo, v. 6, n. 1, p. 20-37, jan./abr. 2012.

OLIVEIRA, G. A.; PACHECO, M. M. Mercado Financeiro: Objetivo e Profissional. $3^{\text {a }}$. ed. São Paulo: Editora Fundamento. 296p. 2017.

ORSATO, R. J. Sustainability Strategies: When does it pay to be green? ISEAD Business Press. p. 3-208, 2009.

PAGE, Y. L. er al. Sensitivity of climate mitigation strategies to natural disturbances.

Environmental Research Letters, v. 1.8, 2013, pp.1-6.

PENTEADO, M. A. B.; FAMÁ, R. Será que o Beta que Temos é o Beta que Queremos. In: Caderno de Pesquisas em Administração. São Paulo. v. 09. n. 3, p. 38-51. jul/set. 2002.

PINKSE, J., KOLK, A. International Business and Global Climate Change. Routledge: New York, NY. 2009.

REZENDE, A. A. C; NUNES, J. G.; PORTELA, S. S. Um Estudo sobre o Desempenho Financeiro do Índice Bovespa de Sustentabilidade Empresarial. In: Revista de Educação e Pesquisa em Contabilidade. v. 2, n. 1, p. 71-93. 2008.

RODRIGUES, A., PAULO, E. Introdução à Análise Multivariada. In: CORRAR, J. L., PAULO, E., DIAS FILHO, J. M. (Coord.). Análise Multivariada: para os cursos de administração, ciências contábeis e economia. 1. ed. 4. reimpr. São Paulo: Atlas, 2012.

SHARPE, W. F. Capital Asset Prices: A Theory of Market Equilibrium under Conditions of Risk. In: The Journal of Finance, vol. 19, n. 3, p. 425-442 sep. 1964.

SILVA, A. F. P. ARAÚJO, R. A. M. SANTOS, L. M. S. Relação da Rentabilidade e o Disclosure de Provisões e Passivos Contingentes Ambientais das Empresas de Alto Potencial Poluídor Listadas na B3. In: Revista Catarinense da Ciência Contábil. v. 17, n. 52, p. 101118. set./dez. 2018.

SOUZA, A. L. R.; GOMES, S. M. S.; ANDRADE, J. C. S.; EUGENIO, T. Por Que Empresas Participam de Iniciativas Empresariais em Clima no Brasil? In: Revista Aidis de Ingeniería y Ciencias Ambientales, v. 11, p. 61-84, 2018.

SOUZA, A. L. R. Empresas Participantes do Índice Carbono Eficiente (ICO2) BM\&FBOVESPA: iniciativas empresariais em clima e retorno e sensibilidade das ações ao risco de mercado. 407f. il. Tese (Doutorado) - Escola Politécnica, Universidade Federal da Bahia, Salvador, 2016. 
RETORNO DAS AÇÕES E SENSIBILIDADE AO RISCO DE MERCADO DAS EMPRESAS PARTICIPANTES DO ÍNDICE CARBONO EFICIENTE (ICO2) DA B3 S.A.: UM ESTUDO COMPARATIVO

TEIXEIRA, E. A.; NOSSA, V.; FUNCHAL, B. O Índice de sustentabilidade empresarial (ISE) e os impactos no endividamento e na percepção de risco. In: Revista de Contabilidade e Finanças da Universidade de São Paulo. v. 22, n. 55. p. 29-44. Jan./fev./mar./abr. 2011.

ZIEGLER, A.; BUSCH, T.; HOFFMANN, V.H. Disclosed corporate responses to climate and stock performance: an international empirical analysis. In: Energy Economics. v.33, p.12831294. 2011.

ZIEGLER, A. Is it Beneficial to be Included in a Sustainability Stock Index? A Panel Data Study for European Firms. In: Environ Resource Econ. v. 52: p. 301-325. 2012. 